\title{
EXAMINING THE EFFECTIVENESS OF LANGUAGE-SWITCHING PRACTICE FOR REDUCING CROSS-LANGUAGE COMPETITION IN L2 GRAMMATICAL PROCESSING
}

Kevin McManus, Pennsylvania State University, USA, kmcmanus@psu.edu

\begin{abstract}
This study examined the extent to which language-switching practice enhanced L2 learners' L2 grammatical processing by improving language selection abilities. Thirty-six Englishspeaking learners of French completed the same language-switching practice of L1 and L2 sentences, but received different types of pre-practice explicit information (EI) designed to address L2 learning difficulties resulting from crosslinguistic influence: one group $(n=17)$ received EI about English-French differences for viewpoint aspect, and a second group $(\mathrm{n}=$ 19) received EI about viewpoint aspect in French only. This design investigated the extent to which pre-practice linguistic knowledge moderated the effectiveness of the languageswitching practice. Longitudinal analyses showed that increasing amounts of practice improved language selection abilities (increased accuracy, reduced reaction time costs), but only for learners who received EI about L1-L2 differences. These findings that languageswitching was moderated by type of pre-practice EI have important implications for theories of L2 learning and instruction.
\end{abstract}

Key words: Grammatical processing, Language-switching, Practice, French, Crosslinguistic influence, Second language acquisition 
A major focus of second language (L2) acquisition research to date has sought to understand the competition and relationships between a speaker's different languages (Abutalebi \& Green, 2007; Ellis, 2006; MacWhinney, 2012; O’Grady, 2005, 2013). This evidence base has shown that the accuracy and speed of L2 processing tends to be reduced (i) when the same linguistic cues in L1 and L2 index different meanings (e.g., word order in English and German; Ellis, 2006; MacWhinney, 2012) and (ii) when L2 speakers switch between languages, especially amongst unbalanced bilinguals (and/or L2 learners) and when switching into the dominant L1 (Abutalebi \& Green 2007; Bobb \& Wodniecka, 2013; Costa \& Santesteban, 2004; Meuter \& Allport, 1999). In addition, investigations of cross-language relationships in the bilingual brain have shown parallel activation of a speaker's languages (Marian \& Spivey, 2003; Wu \& Thierry, 2010), indicating that use of one language activates other known languages. A consequence of this parallel activation is that L2 speakers must develop language selection mechanisms so that the appropriate language can be selected when required (Calabria, Costa, Green \& Abutalebi, 2018; Green, 1998). Difficulties associated with language selection are one explanation for L2 processing problems resulting from cross-language competition.

Despite this understanding, however, very little research has examined the extent to which evidence about cross-language competition can be used to enhance L2 processing. To date, a very small body of research has shown that practice involving language switching can improve L2 speakers' language selection abilities: lexical processing practice of cued pictures in L1 and L2 led to reduced reaction time (RT) costs when switching between languages, including switches into the dominant L1, understood to be the most difficult type of language switch (Wu, Kang, Ma, Gao \& Guo, 2018; Zhang, Kang, Wu, Ma \& Guo, 2015).

While research indicates that language-switching practice can improve L2 speakers' language selection abilities, this evidence base, however, has predominantly used posttests to 
evaluate the effectiveness of the practice, without examining performance during the practice (e.g., Gollan \& Prior, 2013; Zhang et al., 2015, but see Timmer et al., 2019 and Wu et al., 2018 who present mean RT and accuracy scores for each practice session). While posttest evidence can inform understanding about the types of knowledge created/developed from practice, not well understood are the processes involved in the development of that knowledge (DeKeyser 1997, Leow, 2015; McManus \& Marsden, 2019a). In addition, averaging RT and accuracy scores over the course of the practice potentially misses critical information about the trajectories of L2 processing (e.g., roles for knowledge creation and/or restructuring and their potential influences on L2 processing trajectories, see McManus \& Marsden, 2019a; Solovyeva \& DeKeyser, 2018). In sum, evidence to date that languageswitching practice improves language selection abilities is indirect. This is because either (i) performance during the training is not examined or (ii) analyses average performance over the course of the practice. To advance this research program, longitudinal research is needed that tracks L2 speakers' item-by-item processing over the course of the practice in order to understand how L2 speakers' language selection abilities develop over time and what role practice plays in that development.

Building on this line of research, McManus and Marsden (2017, 2018, 2019a, 2019b) provided extensive language-switching practice involving grammatical processing of L1 and L2 sentences (unlike any previous research). The target feature was viewpoint aspect in French, a semantic category that expresses how speakers present or view events in time (Smith, 1997): Past perfective viewpoints present events as complete (e.g., elle a marché au parc [hier], 'she walked to the park [yesterday]'), past habitual viewpoints present events as regularly repeated (e.g., elle marchait au parc [tous les jours], 'she walked to the park [everyday]', 'she used to walk to the park [everyday]'), and past ongoing viewpoints present events as in progress (e.g., elle marchait au parc [hier], 'she was walking to the park 
[yesterday]'). This study was designed to address well-documented learning difficulties in English speakers' processing and use of viewpoint aspect in French (Ayoun, 2013; Izquierdo \& Collins, 2008; McManus, 2013, 2015), understood to be the result of L1-L2 cue validity differences (MacWhinney, 2012; McManus \& Marsden, 2019b).

Two treatments provided the same language-switching practice, but with different types of pre-practice explicit information (EI) to address L2 processing difficulties resulting from L1-L2 form-meaning (or cue validity) differences (MacWhinney, 2012). One group received EI about English-French differences and similarities for viewpoint aspect (L2+L1 group) and a second group received EI about viewpoint aspect in French only (L2+L1prac group). Results showed that the accuracy and speed of L2 processing improved over the course of the practice, and at immediate and delayed posttests (six weeks later) in online (self-paced reading) and offline tests (comprehension tests on reading and listening, semispontaneous oral production), but only for learners who received EI about L1-L2 differences (L2+L1 group). Analyses of L2 processing over the course of the practice indicated betweengroup similarities in each practice session for mean performance (accuracy, RT), but item-byitem analyses showed different performance trajectories. In the L2+L1 group, performance was initially slow and inaccurate, but became faster and more accurate with increasing amounts of practice. In the L2+L1prac group, however, accuracy and speed remained mostly stable over the course of the training (i.e., neither improving nor getting worse).

While this evidence suggested that EI about L1-L2 differences plus comprehension practice benefited the accuracy and speed of L2 processing (in online and offline posttraining tests and over the course of the practice), very little is known about the extent to which regularly switching between languages contributed to these learning gains, if at all. It is possible that the online and offline gains resulted from opportunities to switch between languages, thereby potentially improving learners' language selection abilities and reducing 
the effects of cross-language competition, understood to be the cause of the learning difficulty. In which case, the interaction of language-switching practice with EI about L1-L2 differences potentially led to McManus and Marsden's (2019a) previously-documented L2 processing gains. If this hypothesis were correct, language selection improvements might be less detectable for learners who received EI about L2 only, arguably because providing EI about L2 did not address the cause of the learning problem, thus potentially reducing the effectiveness of the practice (Henry, Culman \& VanPatten, 2009). Understanding how this language-switching practice potentially contributed to L2 learning outcomes therefore has important implications for both theories of L2 learning (e.g., the extent to which practice effects are moderated by pre-practice EI, see DeKeyser, 1997) and instructed foreign language learning (e.g., the extent to which knowledge about L1-L2 differences and a principled L1 use can benefit L2 learning and use, see McManus \& Marsden, 2017).

The current study addressed these gaps by examining L2 learners' item-by-item switching of L1 and L2 sentences with and without EI about L1 to better understand (i) how language-switching performance during the practice contributed to the previously-reported L2 processing improvements and (ii) how EI about L1 contributed to performance during the language-switching practice. No previous research has investigated the extent to which language-switching involving grammatical processing of L1 and L2 sentences can reduce switching costs, what the longitudinal trajectories of these switch costs are, and the extent to which language-switching practice is moderated by the type of pre-practice EI.

\section{$\mathrm{L} 1$ influence in $\mathrm{L} 2$ processing}

Prior language knowledge and experience, especially from a lifetime of L1 use, can majorly influence L2 processing at all stages of learning (Ellis, 2006; O’Grady, 2012, 2013; MacWhinney, 2012; VanPatten, 2015). This is because (i) the same linguistic cues in L1 and 
L2 (e.g., verbal forms, word order) can vary how they index the same meanings

(MacWhinney, 2012) and (ii) prior processing experience can influence learners' attention to linguistic cues (Ellis, 2006, 2008). English-French differences for expressing past habitual (e.g., he played football everyday) and past ongoing (e.g., he was playing football yesterday) viewpoint aspect meanings are one example of this learning problem (Smith, 1997; McManus, 2015; McManus \& Marsden, 2019b). Although both English and French can express the same viewpoint aspect meanings, they do so in different ways: past habituality and past ongoingness are mapped to separate linguistic cues in English (Simple Past and Past Progressive, respectively, Smith, 1997; Tagliamonte \& Lawrence, 2000), but French maps both meanings to the same linguistic cue (Imparfait, Hoffman, 1995), as in Table 1.

Table 1 here

L2 research has shown considerable difficulties among English speakers in expressing these meanings in French (Ayoun, 2013; Howard, 2005; McManus, 2013, 2015), whereas speakers that index viewpoint aspect meanings in similar ways (e.g., in Spanish-French) show considerably fewer difficulties (Amenós-Pons, Ahern \& Gujarro-Fuentes, 2017; Lorenzo, 2002). L1-L2 cue validity differences (English-French) and similarities (SpanishFrench) are one explanation for these findings. In addition, L2 research involving English speakers has shown use of the past perfective Passé Composé to express habituality instead of Imparfait (e.g., parfois je suis allée* visiter mes amis à Paris le weekend [sometimes I went*-PAST PERFECTIVE to visit my friends in Paris at the weekend], from Howard, 2005, p. 188), but then Imparfait is appropriately used to express ongoingness (Howard, 2005; McManus, 2015, see also Ayoun, 2004; Starren, 2001). This usage reflects (i) how English maps viewpoint aspect meanings to verbal forms (i.e., English speakers express habituality using a past 
perfective form as in their L1) and (ii) a need to grammatically distinguish habituality from ongoingness, as done in their L1: Past Progressive for ongoingness and Simple Past for habituality. Taken together, research suggests that L1 knowledge and experience can play an important role in understanding L2 learning outcomes.

\section{Addressing L1 influence in L2 processing}

Resolving this English-French learning problem, understood to be the result of L1-L2 cue validity differences (MacWhinney, 2012; McManus \& Marsden, 2019b), requires the creation and/or development of linguistic knowledge (or processing routines) that is both appropriate for L2 processing and potentially distinct from that used in L1 processing (O’Grady, 2005, 2013, 2015). This is because L1-L2 cue validity differences render L1 processing routines unsuitable for L2 processing (O’Grady, 2013; MacWhinney, 2012). For example, although word order can be used to interpret subject-object information in English (e.g., the cat ${ }^{-\mathrm{SUBJECT}}$ chased the boy-OBJECT $)$, word order is not a reliable cue for subject-object information in German: die Katze $e^{-S U B J E C T}$ jagte den Jungen ${ }^{-O B J E C T}$ and den Jungen ${ }^{-O B J E C T}$ jagte die Katze $e^{-S U B J E C T}$ both mean 'the cat chased the boy' despite having different word orders, Jackson, 2007). The English-speaking learner of German must develop L2 appropriate knowledge that operates on case marking cues instead of word order cues to interpret subjectobject information. Therefore, since L1 processing routines can be inefficient and inappropriate for L2 processing, new processing routines are required when L1 and L2 use the same cues to index different meanings (e.g., L2 processing routine: case marking cues = subject-object information; L1 processing routine: word order cues $=$ subject-object information)

Although creating and/or developing L2 appropriate knowledge is necessary, it can be slow, inefficient, and considerably taxing on internal processing pressures, depending on the 
nature of the L1-L2 relationship (O'Grady, 2005). Regular and frequent use of the newly created/developed processing routine is needed for strengthening and automatization, thus allowing routines to become less costly and more available for rapid use (see also DeKeyser, 1997). The creation and/or development of L2 appropriate processing routines, however, is one part of the L2 learning process. L2 learners must additionally develop appropriate language selection mechanisms that allow for the appropriate routine to be selected when required (Green, 1998). In other words, L2 learning requires not only the creation and/or development of L2 appropriate knowledge (that is potentially independent from L1 knowledge), but also the creation/development of language selection mechanisms so that this knowledge can be (rapidly) selected from competing knowledge sources and made available for use (Calabria et al., 2018).

Green (1998) hypothesized that language selection (i.e., the ability to select the appropriate processing routine) involves a series of domain-general inhibitory control processes that allow dominant or competing responses to be inhibited (Miyake, Friedman, Emerson, Witzki, Howerter \& Wagner, 2000; Stahl, Voss, Schmitz, Nuszbaum, Tüscher, Lieb \& Klauer, 2014). Language knowledge (e.g., a lemma in lexical processing, a routine in grammatical processing) is hypothesized to be associated with language-specific tags (e.g., L1 tags for L1 routines) and that efficient inhibitory control can prevent nontarget language selection by tag suppression (see also Green \& Abutalbei, 2013; Spivey \& Marian, 1999). To illustrate for past ongoingness in English (L1) and French (L2), the routine "Past Progressive $=$ Ongoingness" is tagged for L1 and the routine "Imparfait + Imparfait = Ongoingness" is tagged for L2 (see McManus \& Marsden, 2017). Language selection is therefore hypothesized to require inhibitory control processes so that L1-tagged routines can be suppressed during L2 processing and vice versa during L1 processing. 
Research testing these proposals has examined the accuracy and speed of performance on inhibitory control tests (e.g., Stroop test) and language processing/production tasks. L2 speakers with more efficient inhibitory control (i.e., those showing smaller interference/switch costs) have been shown to exhibit more accurate and faster performance in picture naming tasks (Linck, Hoshino \& Kroll, 2008), word recognition tasks (Mercier, Pivneva \& Titone, 2014), and production and perception tasks (Darcy, Mora \& Daidone, 2014, 2016). Taken together, L2 speakers' performance in interference management tests (e.g., Stroop) appears related with performance in language tests tapping similar skills, including switching between languages, suggesting an important role for efficient inhibitory control mechanisms in facilitating L2 processing. Inefficient inhibitory control mechanisms (i.e., difficulties associated with managing interference) are therefore hypothesized to reduce the accuracy and speed of L2 processing because dominant/competing responses are more difficult (and costly) to inhibit, leading to erroneous selection of the inappropriate processing routine. These conclusions are also borne out in studies comparing language processing changes in switch versus non-switch trials. In switch trials, learners process consecutive stimuli from different languages, L1>L2, L2>L1, but, in non-switch trials, learners' process consecutive stimuli from the same languages, L1>L1, L2>L2. This body of research shows that L2 speakers tend to respond less accurately and more slowly during switch trials than in non-switch trials (Costa \& Santesteban, 2004; Costa, Santesteban \& Ivanova, 2006; Meuter \& Allport, 1999), indicating better performance when the same task requires use of a single language (e.g., picture naming in L2 only) rather than use of both languages (e.g., naming pictures in L1 and L2). In addition, comparisons of L1>L2 and L2>L1 switches have shown that not all switches appear symmetrical: switching from L2 into L1 appears more difficult (i.e., less accurate and slower) than switching from L1 into L2 (Costa \& Santesteban, 2004; Fink \& Goldrick, 2015; Meuter \& Allport, 1999). One explanation for these findings is that 
language experience and language dominance can influence the efficiency of inhibitory control mechanisms (Abutalebi \& Green, 2007). Selecting a weaker language (L2) over a dominant language (L1) is understood to be more difficult for L2 learners (i.e., unbalanced bilinguals) because of differences in the activation levels of language systems and/or representations. This is because a learner's weaker language (e.g., L2) is assumed to have a lower baseline level of activation than the dominant language (e.g., L1). In such situations, typical of L2 learners in L1-dominant contexts (Green \& Abutalebi, 2013), less inhibitory control is needed to select L1 over L2 given the relatively higher levels of activation of the dominant L1, but more inhibitory control is needed to select L2 over L1 given the lower activation level of the weaker L2 (Abutalebi \& Green, 2007). Therefore, among L2 learners, L2>L1 switches are understood to be more difficult (or costly) than L1>L2 switches for two related reasons. First, selecting the L2 requires strong inhibition of L1. Second, switching into L1 requires reversal of previous inhibition used for selecting the L2 (Green, 1998). ${ }^{1}$

\section{Training language selection mechanisms}

Given that inhibitory control mechanisms are understood to play an important role in managing cross-language competition (Abutalebi \& Green, 2007; Calabria et al., 2018; Green, 1998), an important question for SLA researchers is the extent to which these mechanisms are amenable to improvement through practice (for review, see Hussey \& Novick, 2012). In other words, if a speaker's processing abilities can be improved through practice, to what extent might these enhanced cognitive processing abilities benefit language processing?

L2 proficiency is understood to be a major variable underlying L2 learners' language selection mechanisms because L2 appropriate knowledge must exist for language selection mechanisms to be created and/or optimized (Costa \& Santestaban, 2004; Costa et al., 2006). 
Research with L2 learners has repeatedly demonstrated that the creation and/or development of L2 knowledge is possible (McManus, 2015; Roberts \& Liszka, 2013), but that the learning difficulty resides in selecting L2 knowledge from competing sources (e.g., L1 knowledge) and rapidly deploying it for real-time use (Kaan, 2014; MacWhinney, 2005), understood to require efficient inhibitory control processes. At the same time, research with very proficient L2 users indicates that specific types of language experience can enhance inhibitory control mechanisms (Abutalebi \& Green, 2016; Tu, Wang, Abutalebi, Jiang, Pan, Li, Gao, Yang, Liang, Lu \& Huang, 2015), especially in contexts that allow for language-switching in daily life (Garbin, Costa, Sanjuan, Forn, Rodriguez-Pujadas, Ventura, Belloch, Harnandez \& Avila, 2011; Prior \& Gollan, 2011). Therefore, contexts that require regular languageswitching appear to benefit a speaker's inhibitory control mechanisms, thus indicating that sufficient opportunities for meaningful language-switching could potentially improve L2 learners' language selection mechanisms and, by extension, language processing.

One recent line of research building on this evidence base has examined the extent to which language-switching practice can improve L2 learners' language selection abilities (e.g., Kang et al., 2018; Timmer, Calabria \& Costa, 2019; Wu et al., 2017). In other words, can the cognitive mechanisms understood to underlie language selection abilities (i.e. inhibitory control) be improved with practice? And if practice can lead to improved performance of specific cognitive mechanisms, to what extent do these practice benefits result in improved language selection abilities, as evidenced through reduced switch costs? To date, a very small body of research has examined performance on cued picture-naming tasks in L1 and L2 (e.g., naming a picture in L1 or L2 depending on the picture's background colour). Results have shown two important trends. First, language-switching practice improved performance on post-practice, non-linguistic inhibitory control tasks (e.g., colourshape decision task in Timmer et al., 2019; AX-CPT in Zhang et al., 2015). Second, some 
evidence indicates that switch costs reduced during the practice (Timmer et al., 2019; Wu et al., 2018; Zhang et al., 2015). Taken together, these results indicate that short-term practice that required learners to regularly switch between L1 and L2 improved inhibitory control mechanisms, which, furthermore, appeared to translate into improved language selection abilities, as evidenced by reduced switch costs.

As previously noted, however, this previous research examined language switching practice involving cued picture naming only with either balanced bilinguals (CatalanSpanish, Timmer et al., 2019) or L2 learners (Chinese-English, Spanish-English, Kang et al., 2018; Prior \& Gollan, 2011; Wu et al., 2018). Furthermore, the effectiveness of the practice in reducing switch costs was measured using averaged switch costs per session only, without examining learners' item-by-item performance over the course of each practice session. Understanding the nature of this performance is critical to understanding the relationships between practice and performance. In addition, previous research has not examined the effectiveness of language-switching during different practice conditions, including, with different language features, with different amounts of practice, and over different practice schedules. One important variable that has not yet been investigated is the extent to which L2 speakers' pre-practice knowledge moderates the effectiveness of language-switching practice for enhancing language selection abilities. In line with previous research examining practice effects, it seems likely that L2 learners' prior knowledge could interact in important ways with the practice (see DeKeyser, 1997), to the extent that L2 learners' without L2 appropriate linguistic knowledge would benefit less from language-switching practice because L2 appropriate knowledge must exist in order for language selection mechanisms to be optimized.

In sum, although research to date suggests benefits for language-switching practice in improving L2 speakers' language selection abilities, not yet investigated is the extent to 
which these language-switching practice benefits extend to other types of language processing, including grammatical processing, what the longitudinal trajectories of switch costs are, and the extent to which prior linguistic knowledge moderates the effectiveness of this practice. The current study sought to address these gaps in previous research.

\section{Current study}

The current study examined the longitudinal trajectories of L2 learners' item-by-item switching of L1 and L2 sentences over the course of language-switching practice, thus extending previous research comparing mean switch costs across practice sessions only (Timmer et al., 2019; Wu et al., 2018). In addition, the current study examined the extent to which previously-reported benefits of language-switching practice involving lexical processing extended to grammatical processing. Lastly, to better understand how languageswitching performance during the practice contributed to McManus and Marsden's previously-reported L2 processing improvements, both during the practice (McManus \& Marsden, 2019a) and at the posttests (McManus \& Marsden, 2017, 2018), the current study examined the extent to which different types of pre-practice explicit information (about L1L2 differences vs. about L2 only) contributed to switch cost changes over time. In these ways, this study advances knowledge and understanding about the effectiveness of languageswitching practice for improving language processing. The current study sought to address the following research questions:

- To what extent do L2>L1 and L1>L2 switches (accuracy and RT) change over time with increasing amounts of comprehension-based, language-switching practice?

- To what extent do switch trajectories change following different types of pre-practice explicit information (about L1-L2 differences vs. about L2 only)? 


\section{Method}

Participants

Participants were 36 university learners of French as a foreign language in semester two of a four-year Bachelor of Arts Honours degree program in French at a British university. All participants were L1 (British) English speakers, aged 18-21 (mean = 19.2, SD = 0.5), had completed A2-level French (English school leaving qualification, equivalent to CEFR level B2, typically after 700-800 hours of instruction), and had not spent more than six weeks abroad in a French-speaking country (mean $=3$ weeks, $S D=5.6$ ). Mean years learning French was $10(\mathrm{SD}=2.7)$. Participants reported infrequent use of French (mean $=2.8$ hours per week, $\mathrm{SD}=0.8$ ), exclusively used at university (in classes, during French club meetings with other students). No participant reported use of French outside university study.

Target feature: French Imparfait

The target feature was French Imparfait (IMP) verbal morphology, a past tense form used to express past habituality and ongoingness (e.g., il jouait au foot - 'he used to play/was playing football'). This feature was selected because L2 research has repeatedly shown that its full set of functions are late-acquired due to functional complexity, including complex L1-L2 formmeaning mapping differences (see Table 1; Bartning \& Schlyter, 2004; Howard, 2005; McManus, 2013, 2015). All exemplars of IMP were third-person singular forms: 25 regular (e.g., jouait 'play') and 23 irregular (e.g., finissait 'finish') verb types balanced across 48 lexical verb types: twelve states (e.g., be happy), twelve activities (e.g., run in the park), twelve accomplishments (e.g., walk to the shop) and twelve achievements (e.g., arrive home).

Study design 
This study is part of a larger project that included three instructional treatments and a control group (see McManus \& Marsden, 2017). Described here are the two treatments that included language-switching practice: $\mathrm{L} 2+\mathrm{L} 1$ and L2+L1prac. The other treatment (L2-only) included comprehension practice of French sentences only (i.e., no language switching practice). The L2+L1 treatment group received EI about English (L1) and French (L2) form-meaning mappings for viewpoint aspect plus comprehension practice of English and French sentences. The L2+L1prac group received EI about French (L2) form-meaning mappings for viewpoint aspect only plus comprehension of English and French sentences. The only difference between these treatments is that the $\mathrm{L} 2+\mathrm{L} 1$ group received EI about English. The languageswitching practice received by the groups was the same. Table 2 summarizes these differences.

Table 2 here

Participants were randomly assigned to a treatment using matched randomization based on pretest performance, which resulted in 17 learners in the $\mathrm{L} 2+\mathrm{L} 1$ treatment group and 19 in the $\mathrm{L} 2+\mathrm{L} 1$ prac treatment group. Pretest scores showed no reliable between-group differences for knowledge of the target feature in online self-paced reading tests and offline comprehension tests in reading and listening (negligible Cohen's $d$ effect sizes with 95\% confidence intervals for $d$ that included zero, see McManus \& Marsden, 2018), indicating between-group equivalence for knowledge of the target feature prior to the treatments.

Treatments were administered one-to-one with laptops using E-Prime 2.0 and delivered in four 45-minute sessions over three weeks, totalling 3.5 hours. Sessions one and two were delivered in week two, session three in week three, and session four in week four. 
Each session had a different instructional focus on the meanings expressed by IMP: Session 1, ongoingness in the past (IMP) vs. present (Present tense); Session 2, habituality in the past (IMP) vs. present (Present tense); Session 3, past ongoingness (IMP) vs. past habituality (IMP); Session 4, past ongoingness (IMP) vs. past habituality (IMP) vs. past perfectivity (Passé Composé). Sessions one and two presented information that was new (i.e., within the experiment) and involved single clause stimuli only (e.g., elle jouait au foot, "she was playing football'). Session three combined information about ongoingness and habituality that had already been experienced in sessions one and two, but applied to twoclause sentences (e.g., elle mangeait un sandwich quand la cloche a sonné, 'she was eating a sandwich when the bell rang'), thus steadily increasing the complexity of the processing task (as recommended in previous training research, e.g. Hussey et al., 2017). Session four included information that had been experienced in all three previous sessions. All materials are available on IRIS. A description of the treatments provided in Session 1 is provided in the Appendix.

Instructional treatments

Both treatments included EI about French IMP and language-switching practice interpreting English and French sentences. The L2+L1 treatment additionally included EI about equivalent English forms (Past Progressive, Simple Past, used to).

EI about L2. Pre-practice EI was first provided for approximately five minutes at the start of each session and depicted conceptual-semantic information using a short video, image, or sound file of events. Ongoingness in present versus past was the instructional focus in Session 1, for example. Ongoingness was depicted using a ten-second video of a man eating an apple, in which the apple was never fully eaten. Learners were then asked to think about 
how they would describe in L2 what they just saw in the video (e.g., he is eating an apple). Then the appropriate L2 aural and written forms were presented, and information given about how to interpret their meaning. For example, French verb endings can be used to distinguish between past ongoingness and present ongoingness (e.g., il jouait - Past IMP 'he was playing', il joue - Present tense 'he is playing'), and so watching/listening out for verb endings can be helpful to distinguish ongoingness in the past vs. present in French. Both $\mathrm{L} 2+\mathrm{L} 1$ and $\mathrm{L} 2+\mathrm{L} 1$ prac treatment groups received this EI.

Additional EI about L1. This pre-practice EI followed the exact same design as the EI about L2: using the same videos and images to depict conceptual-semantic information (e.g., concept of ongoingness), asking learners to think how they might describe what was depicted in the videos/images, presentation of grammatical forms used to describe that concept (e.g., 'he is eating an apple' vs. 'he was eating an apple' for the concept of ongoingness), and then information to aid processing (e.g., attend to the auxiliary in 'is going' and 'was going' to tell if the event referred to took place in the present (look/listen out for 'is') or in the past (look/listen out for 'was'). Additional EI about the L1 was received by the L2+L1 group only.

Language-switching practice in L2 and L1. Pre-practice EI was immediately followed by L2 and L1 comprehension practice in listening and reading that forced learners to attend to formmeaning mappings expressed by IMP, Passé Composé or Présent (for French) or by Past Simple, Past Progressive, Present Simple, or Present Progessive (for English) (see Marsden, 2006; VanPatten, 2015). Learners selected the stimulus's meaning from two options in Sessions 1, 2, and 3 and from three options in Session 4. Stimuli were single clause in Sessions 1 and 2 (e.g., Il court dans la rue 'he is running in the street') and two clauses in 
Sessions 3 and 4 (e.g., Elle mangeait un sandwich quand la cloche a sonné ('She was eating a sandwich when the bell rang'). An image (e.g., sandwich) plus a bracketed infinitive (e.g., manger 'eat') appeared alongside two-clause stimuli so that learners knew which verb to interpret.

The practice contained 712 stimuli in total (552 French and 160 English). 96 French and 32 English in each of Sessions 1 and 2, 144 French and 48 English in Session 3, and 216 French and 48 English in Session 4. The ratio of French to English stimuli was 3:1 in Sessions 1-3 and 9:2 in Session 4. All learners completed the same amounts of practice and received the same stimuli, though the stimuli within each practice session were randomized by E-Prime. The stimulus appeared first (e.g., jouait au foot quand sa petite amie est arrivée 'was playing football when his girlfriend arrived'), then after $2500 \mathrm{~ms}$ (for two-clause stimuli) and 500ms (for single-clause stimuli) the response options appeared and stayed on screen until a response was pressed. For aural stimuli, the response options did not appear until after the full stimuli had played. Thus, for all practice items, responses were not time pressured. Responses could not be changed after initial selection.

Correct/incorrect feedback was shown immediately after each response. Additional EI was provided during the practice following incorrect responses only, which was infrequent and occurred in very (statistically) similar amounts in all treatments.

Data analysis

E-Prime collected accuracy and reaction time data for every response. For accuracy, responses were coded as correct (1) or incorrect (0). Reaction times were calculated in milliseconds from the onset of response options to response selection.

Two types of switch cost were calculated: (i) an L1 stimulus immediately followed by an L2 stimulus (L1>L2 switch) and (ii) an L2 stimulus immediately followed by an L1 
stimulus (L2>L1 switch). All switches (L1>L2, L2>L1) therefore included two different stimuli (L1 or L2). Two raters each manually identified and extracted from E-Prime 100\% of stimuli used for calculating switches. Inter-rater reliability of stimuli identification and extraction $(\mathrm{k}=0.97)$ indicated high reliability of stimulus identification and extraction (Plonsky \& Derrick, 2016).

For accuracy, switches were calculated using raw accuracy data collected from EPrime. A switch was coded as correct only if both items in the switch were correct. A switch was coded as incorrect if either (i) one item in the switch was correct and one was incorrect and (ii) if both items in the switch were incorrect. For RT, switches were calculated for accurate switches only (following Kang et al., 2018; Timmer et al., 2019). For each item, RTs of more than 3 SDs above the group mean were considered as extremely slow and RTs of more than 3 SDs below the mean were considered as extremely fast. RTs that fell into these categories were removed.

A switch cost was calculated separately for each switch (L1>L2, L2>L1) by subtracting the RT of the second stimulus from the RT of the first stimulus. For example, an L1>L2 switch was calculated by subtracting the RT of the L2 stimulus from the RT of the L1 stimulus. This calculation quantifies the amount of response conflict between the current and the preceding test item (Meuter \& Allport, 1999). A high switch cost suggests increased response conflict between switching between languages and a low switch cost suggests reduced conflict.

Switch accuracy and RT were analysed in R (R Core Team, 2018), with separate analyses for accuracy and RT and for each session because each session had a different instructional focus (as previously described) and not all sessions included the same number of practice items. Accuracy was analysed with logit mixed-effects analyses (Jaeger, 2008) using the lme4 package (Bates, Maechler, Bolker \& Walker, 2015). Mixed-effects linear regression 
analyses (Baayen, Davidson \& Bates, 2008) using nlme (Pinheiro, Bates, DebRoy, Sarkar \& R Core Team, 2018) were used to analyse the RTs of switch costs over the course of each practice session. Explanatory variables were as follows: Group (L2+L1, L2+L1prac), Switch type (L1>L2, L2>L1) and Item (i.e., ranked switch). These were entered into the models as fixed effects. Subject and items were added as cross-random factors.

For each session, multiple models were constructed, and the most plausible model was found through comparison (see Table 3 for accuracy and Table 4 for RT). Starting with the simplest model, new parameters were added to the model one at time (Field, Miles \& Field, 2012; Murakami, 2016). Models were compared as they were built using maximumlikelihood estimation (Field et al., 2012).

Table 3 here

Table 4 here

First, a base-line model was fitted in which only the intercept was included, then a model was fitted that allowed the intercept to vary over Subjects. Finally, to verify whether allowing the intercepts to vary improved the model fit significantly, the models were compared using AIC (Akaike Information Criterion) and the anova function. The final models were then built by adding Group, Trial, and then Item as fixed-effect factors, followed by a random slope added for the effect of Item (thus allowing the effect of Item to vary across Subjects, because items were randomly ordered within each session for each participant), and then a Group x Trial x Item fixed-effect interaction. After adding each new parameter to the model, AIC and anova were used to verify whether its addition significantly improved the fit of the model. A parameter was only excluded from the optimal model if its 
addition significantly increased the AIC value (see Cunnings \& Finlayson, 2015; Field et al., 2012).

For all analyses, the alpha was set at .05. To interpret effect estimates and magnitudes of change, $95 \%$ CIs and $\mathrm{R}^{2}$ effect sizes are presented. CIs with short intervals that do not include zero can be considered reliable indicators of change (Field et al., 2012; Larson-Hall \& Plonsky, 2015). As with other standardized effect size statistics, $\mathrm{R}^{2}$ was used as a summary index for statistical models to evaluate model fit, compare magnitudes of effect across studies, and can be used for meta-analysis (Nakagawa \& Schielzeth, 2013). $\mathrm{R}^{2}$ values range from 0-1 and are used to estimate how much of the variance in performance can be accounted by the entire model (conditional $\mathrm{R}^{2}$ ) and by the fixed effects only (marginal $\mathrm{R}^{2}$ ), computed using the MuMIn package (Bartoñ, 2018) in $\mathrm{R}$ ( $\mathrm{R}$ Core Team, 2018; see Table 5). $\mathrm{R}^{2}$ values around $.18, .32$, and .51 are interpreted as small, medium, and large, respectively, in terms of the explained variance they represent (Plonsky \& Ghanbar, 2018). Because MuMIn does not calculate $\mathrm{R}^{2}$ values for each individual fixed effect, the estimate, its $95 \%$ CIs, and its p-value are used to interpret each fixed effect and its contribution to the model.

Table 5

\section{Results}

\section{Switch accuracy}

Table 6 shows the effects of the fixed factors and the Group x Trial x Item interactions in all practice sessions (see Figures 1 and 2 for corresponding plots).

\section{Figure 1}

Figure 2 
Table 6

Switch accuracy over the course of all practice sessions was significantly influenced by Group and the interaction between Group and Item ( $\mathrm{p}<.05$, no CIs included zero), as Figures 1 and 2 show. Trial type (L2>L1, L1>L2) appeared to exert few influences on accuracy over time (except in Session 2). These results indicate that the accuracy of switching between languages over time was meaningfully influenced by Group only and not by the direction of the language switch. Figures 1 and 2 illustrate that the nature of this difference is low switch accuracy performance at the beginning of each practice session for the L2+L1 group, with accuracy improving with increasing amounts of practice. In contrast, performance in the $\mathrm{L} 2+\mathrm{L} 1$ prac group is largely stable with inaccuracies spread throughout each practice session (rather than being focused at the beginning of each session). Figure 1 and 2 additionally show that switch accuracy at the end of each practice session is, overall, more accurate in the $\mathrm{L} 2+\mathrm{L} 1$ group than in the $\mathrm{L} 2+\mathrm{L} 1$ prac group.

Posthoc tests were carried out to understand these Group x Item interactions (see Table 7). Results showed that the accuracy of switching between languages only improved significantly over time for the $\mathrm{L} 2+\mathrm{L} 1$ group, in all sessions $(\mathrm{p}<.05$, no CIs include zero). For L2+L1prac learners, however, accuracy did not change significantly as function of the practice ( $\mathrm{p}>.05$, all CIs included zero). Taken together, accuracy improved as a function of the practice for $\mathrm{L} 2+\mathrm{L} 1$ learners only.

\section{Table 7}




\section{Switch RT}

Table 8 shows the effects of the fixed factors and Group $\mathrm{x}$ Trial $\mathrm{x}$ Item interactions in all practice sessions for switch RT (see Figures 3 and 4 for corresponding plots).

Figure 3 here

Figure 4 here

Table 8

In contrast to accuracy, RT performance was significantly influenced by trial type in all sessions. Group effects were found in practice Sessions 2 and 4 only. These results indicate a consistent effect of trial type on processing speed and that pre-practice EI influenced performance in these practice sessions.

No statistically significant Group $\mathrm{x}$ Item $\mathrm{x}$ Trial interactions in sessions one and three indicated negligible between-group differences for processing speed over time within each trial type (see also Figures 3 and 4), suggesting that, in these practice sessions, type of prepractice EI appeared not to influence switch costs over time. In Sessions 2 and 4, however, results indicated a significant influence of Group on processing speed over time within each trial type. Posthoc tests were carried out to further explore the Group x Trial x Item interactions in Sessions 2 and 4.

Table 9 here

For L1>L2 switches, switch costs did not change over time for either group (see Table 9). All CIs for $b$ included zero, indicating negligible/unreliable change, and all $\mathrm{R}^{2}$ values were 0 . These results indicate that increasing amounts of L1>L2 language-switching practice 
appeared not to majorly affect switch costs and that there was no impact of Group on this performance.

For L2>L1 switches, however, switch costs reduced significantly over time, but only in the L2+L1 group (see Table 9). In this group, no CIs for the $b$ test statistic included zero, indicative of reliable change. $\mathrm{R}^{2}$ values were small, indicating that ranked item number explained a small proportion of the variance in both practice sessions, with a slightly stronger effect in Session 2 (see also Figures 3 and 4). An interpretation of the $b$ values indicates that that switch costs reduced by approximately $20 \mathrm{~ms}$ (practice session 2) and $14 \mathrm{~ms}$ (practice session 4) for every additional practice item completed.

In the L2+L1prac group, however, all CIs for $b$ included zero, indicating negligible/unreliable change, and all $\mathrm{R}^{2}$ values were 0 . These results indicate that increasing amounts of language switching practice from L2>L1 appeared not to affect switching costs for this group.

Taken together, these analyses indicate that trial type majorly influenced processing speed, but not processing accuracy. Group effects for accuracy were detected in all sessions because L2+L1 learners' performance was less accurate at the beginning of each session but improved as a function of the practice. Minimal change over time was observed for L2+L1prac learners (see Figures 1 and 2). In terms of RT, effects for Group were detected in sessions 2 and 4 because L2>L1 switch costs reduced over time for L2+L1 learners only. L1>L2 switch costs did not change over time for either treatment group. In other words, the RT cost associated with switching from L2 to L1 reduced with increasing amounts of language-switching practice following pre-practice EI about L1-L2 differences. In addition, the impact of increasing amounts of practice on L2>L1 switch cost trajectories appeared cumulative. Sessions 1 and 2 involved comprehension practice of single clause stimuli, with 
effects detectable in Session 2 only. Session 3 and 4 involved comprehension of two-clause stimuli, with effects only detectable in Session 4 only.

\section{Discussion}

The current study examined the extent to which language-switching practice involving comprehension of French (L2) and English (L1) sentences improved learners' abilities to switch between languages. Two treatments included the same type and amount of language-switching practice, but different types of pre-practice EI: EI about L1-L2 differences (L2+L1 treatment) compared with EI about L2 only (L2+L1prac treatment). This design investigated the extent to which the type of EI received moderated the effectiveness of the language-switching practice. Results showed that switch accuracy improved and switch RTs reduced with increasing amounts of practice in the L2+L1 group, but not in the $\mathrm{L} 2+\mathrm{L} 1$ prac treatment group. In addition, fine-grained analyses of switch types in the $\mathrm{L} 2+\mathrm{L} 1$ treatment group showed that only L2>L1 switch costs reduced over time.

The current study's results indicate, therefore, that language-switching practice alone was an insufficient condition for improving the accuracy and speed of switching between languages. These findings therefore contrast with previous research showing that languageswitching practice was generally effective for reducing switch costs (e.g., Kang et al., 2018; Timmer et al., 2019, but see Prior \& Gollan, 2013). Between-study differences in terms of the nature and the aims of the language-switching practice could explain these differences with previous research.

First, language-switching practice in previous research involved naming lexical items in L1 and L2, whereas this study involved comprehension of sentences in L1 and L2. In Timmer et al.'s practice, for example, participants were required to name a picture (e.g., a candle) in either L1 or L2. Visual cues (a dotted- or solid-line border) indicated the response 
language (i.e., name picture using L1 for picture with solid-line border). In the current study's practice, however, participants attended to multi-word sentences (e.g., she was reading a book) and selected its meaning from selected options (e.g., past vs. present). Participants used word cues (e.g., jouait vs. played) rather than picture-based cues (e.g., dotted- vs. solid-line border) for language selection. Furthermore, lexical processing (used in picture naming) is understood to rely more heavily on lower level processes (e.g., lexical access), whereas sentence processing requires high-level and multi-layered processing, including lexical access, inferencing, and using background information (Grabe \& Stoller, 2013; Lim \& Godfroid, 2015). In addition to differences in the design of the practice, the cognitive demands involved in lexical vs. sentence-level processing are possible explanations for these different findings.

Second, while the aims of previous research and the current study were to improve language selection abilities using language-switching practice, this aim was approached differently. In Kang et al. (2018), for example, participants were familiarized with the practice stimuli before the practice (i.e., Chinese and English pictures and their names). In contrast, the current study provided EI about processing routines to address specific learning problems (interpreting the aspectual meaning of past tense forms). As a result, the current study additionally engaged participants in grammatical learning (i.e., how to appropriately interpret the meaning of an unfamiliar sentence string), whereas the previous research engaged participants in language selection only. This difference (grammatical learning + language selection vs. language selection only) is one likely explanation for the different patterning of results with previous research.

Although these accounts are potential explanations for contrasting findings with previous research, they do not offer an explanation for why the current study's L2+L1 and L2+L1prac treatment groups performed differently, especially since both groups (i) 
completed the same amount and type of practice and (ii) were engaged in both grammatical learning and language selection.

\section{Language representations during language-switching practice}

The current study hypothesized that resolving crosslinguistic influence in L2 processing minimally requires two components. First, the creation and development of new processing routines that are both appropriate for L2 processing and potentially distinct from those used in L1 processing (O’Grady, 2013, 2015; VanPatten, 2015). Second, L2 learners must also develop appropriate language selection mechanisms so the appropriate processing routine can be selected when required (Calabria et al., 2018; Green, 1998). Difficulties associated with effectively inhibiting the inappropriate language are hypothesized to result in selection of an inappropriate processing routine (i.e., crosslinguistic influence). As previously discussed, selecting one processing routine (e.g., L1) over a different one (e.g., L2) necessarily requires that separate routines exist (i.e., that the learner has created a new routine appropriate for L2 processing).

One possible explanation is that not all treatments helped learners create and develop L2 knowledge to the same extent, hypothesized to be an important foundation for languageswitching practice to be effective. Indeed, as also reported in McManus and Marsden (2019b) for L2 processing, minimal accuracy change over time was found for L2+L1prac learners, thus contrasting with L2+L1 learners who showed significant accuracy improvement. Analysis of performance over time showed important differences in processing trajectories, despite the groups being matched for target feature knowledge at the pretest. The provision of EI about L1-L2 differences appears to have negatively influenced processing accuracy at the beginning of the practice, but ultimately led to more accurate performance over time. One explanation for this could be that this EI promoted knowledge creation and/or restructuring, 
which was reflected in the initially inaccurate performance that improved with increasing amounts of practice (see also Solovyeva \& DeKeyser, 2018). Since no similar trajectory was found in the L2+L1prac group and that errors in this group were dispersed across the practice (rather than focused at the beginning of the practice, as found for L2+L1 learners), the $\mathrm{L} 2+\mathrm{L} 1$ prac treatment may have been less effective in helping learners create accurate linguistic knowledge appropriate for L2 processing. In other words, L2+L1 learners appeared to have developed (more) accurate language representations for L2 processing than L2+L1prac learners, which could explain why switch costs reduced for L2+L1 learners only. It seems possible that establishing L2 appropriate knowledge may be a necessary condition for language-switching practice to be effective, and, by extension, for language selection mechanisms to be optimized.

In addition, this account could potentially explain why switch cost reductions among L2+L1 learners appeared slow to develop (negligible change in Sessions 1 and 3): these early sessions may have served to develop and strengthen L2 knowledge, which had to be in place for signatures of language selection to be detected. In other words, Sessions 2 and 4 may have served to (i) consolidate this new L2 knowledge and (ii) develop language selection mechanisms. This seems possible given that Session 1 and 3 introduced new topics, comprehension of one- and two-clause stimuli, respectively, while Sessions 2 and 4 provided further practice of one- and two-clause stimuli, respectively.

Taken together, language-switching practice reduced switch costs among L2+L1 learners because only these learners had created and developed the linguistic knowledge appropriate for L2 processing. This is because accurate knowledge of the target feature appears to be a necessary condition for language selection mechanisms to be optimized. As a consequence, extended opportunities to switch between languages improved L2 learning by developing learners' abilities in language selection, but this could only take place once L2 
knowledge had been established and consolidated. Language-switching practice did not reduce switch costs in the $\mathrm{L} 2+\mathrm{L} 1$ prac treatment group because these learners had potentially failed to create the appropriate L2 knowledge.

\section{Switch cost asymmetries during the practice}

The results showed switch costs asymmetries from the beginning, for both treatment groups, to the extent that initial L2>L1 switches in Session 1 were approximately 500ms slower than L1>L2 switches. However, L2>L1 switches reduced over time for L2+L1 learners, but not for $\mathrm{L} 2+\mathrm{L} 1$ prac learners. These results indicate that language-switching practice had a selective effect on switch costs (L2>L1 switches only). Findings from the L2+L1 group are consistent with Wu et al. (2018), who also found switch cost asymmetries during the practice, with only switches into the L1 (L2>L1) that benefitted from languageswitching practice.

One potential explanation for these findings could be that language-switching practice allowed L2+L1 learners to develop their abilities to apply and overcome inhibition of L1, abilities that can only be detected in L2>L1 switches. Switching from L2 into L1 is understood to be particularly costly because this requires that previous inhibition of L1 must reversed. In other words, inhibition of L1 allows for L2 processing, but then switching into L1 requires overcoming the recently applied inhibition of L1. Furthermore, inhibition of the dominant language is understood to be more difficult than inhibition of the weaker language. While this process of inhibiting the dominant language followed by its reversal was very costly at the beginning, as evidenced by the slower RTs for L2>L1 switches relative to L1>L2 switches in Session 1, frequently carrying out these switches likely benefitted learners' inhibitory control mechanisms thereby allowing L2>L1 switches to appear less costly with increasing amounts of practice. 
It is possible that practice benefits for L1>L2 were not detected because these switches are less costly, as evidenced by the lower reaction time costs in Session 1. Although $\mathrm{L} 1$ processing requires inhibition of $\mathrm{L} 2$, this process is understood to be relatively easier when the weaker language is inhibited. Switching from L1 into L2 therefore requires reversal of a comparatively weaker inhibitory control process, understood to be less costly.

Taken together, therefore, the current study's findings suggest that regularly switching between L2 and L1 developed learners' abilities to apply and overcome inhibition of the dominant L1, understood to be the costliest of language switches. Although the effects of this were not immediately detectable (as evidence by negligible effects of time for L2>L1 switches in Sessions 1 and 3), it seems that regular opportunities to apply and overcome inhibition of the dominant L1 benefitted performance over time. Importantly, however, this enhanced ability to apply and overcome inhibition of the dominant L1 was only detected for learners who had developed accurate L2 knowledge.

\section{Limitations and future research}

The current study's relatively small sample sizes indicate that these findings require replication (Porte \& McManus, 2019). The claims about the effectiveness of languageswitching practice for improving language selection mechanisms also rest on a very small body of evidence, none of which has examined grammatical processing. Nonetheless, this represents an important research agenda for the field if we are to understand practice effects on language processing, especially with regard to understanding the practice of specific cognitive processes that have the potential to improve L2 processing, as in the current study.

As previously mentioned, it appears that the during-practice trends found in the current analysis were consistent with performance on controlled comprehension measures in McManus and Marsden $(2017,2018)$, but future research should investigate how these 
signatures of language selection relate to post-practice performance on non-linguistic tests (e.g., Stroop tests). Furthermore, the designs of future research should incorporate delayed posttesting to understand the durability of language-switching effects on language processing. Questions about the durability of specific practice programs are rarely addressed in the field, but represent important areas for future research to advance knowledge and understanding about instructional effects and their durability.

The findings of between-group differences over time indicates that pre-practice EI likely had an important impact on performance during the practice, especially given that this was the only difference between the treatments. This therefore suggests that languageswitching practice likely interacts with prior language knowledge in important ways. One potential explanation for why switch cost reductions emerged late could be related to amount of language-switching involved in the practice. Previous research set the ratio of L2 to L1 stimuli at 1:1. However, the current study used a lower ratio of L2 to L1 stimuli (3:1 and 9:2) and still detected switch cost improvements. Future research should examine whether there are thresholds for the amount of switching necessary for improvement to be detectable. It seems possible that the amount and frequency of switching could impact the durability of any observed learning effects.

Lastly, the current study's findings suggest that instruction about L1-L2 differences that included both EI about these differences and comprehension practice of L1 and L2 sentences was beneficial for improving L2 processing. These findings, along with a growing body of evidence about the benefits of L1 use in L2 learning (see McManus, 2019; McManus \& Marsden, 2017; Spada, Lightbown, \& White, 2005), have important implications that challenge some contemporary approaches to L2 learning and teaching. For example, in the US, there is growing interest in 'comprehensible input' approaches to L2 teaching that emphasise almost exclusive L2 use in the classroom (see ACTFL, 2014). This is despite 
recommendations from national language teaching associations and a growing body of research that developing learners' awareness and understanding of language, including of L1L2 differences, is necessary for language development (see NSFLEP, 2015). This study's findings build on this work by indicating that incorporating L1 use into L2 learning can play an important role in advancing language development. 


\section{References}

Abutalebi, J., \& Green, D. (2007). Bilingual language production: The neurocognition of language representation and control. Journal of neurolinguistics, 20(3), 242-275.

Abutalebi, J., \& Green, D. W. (2016). Neuroimaging of language control in bilinguals: neural adaptation and reserve. Bilingualism: Language and Cognition, 19(4), 689-698.

American Council on the Teaching of Foreign Languages (2014). The Language Educator, $9(5), 1-68$.

Amenós-Pons, J., Ahern, A., \& Gujarro-Fuentes, P. (2017). L1 French Learning of L2 Spanish Past Tenses: L1 Transfer versus Aspect and Interface Issues. Studies in Second Language Learning and Teaching, 7(3), 489-515.

Ayoun, D. (2004). The effectiveness of written recasts in the second language acquisition of aspectual distinctions in French: A follow-up study. The Modern Language Journal, 88(1), 31-55.

Ayoun, D. (2013). The second language acquisition of French tense, aspect, mood and modality. John Benjamins Publishing.

Baayen, R. H., Davidson, D. J., \& Bates, D. M. (2008). Mixed-effects modeling with crossed random effects for subjects and items. Journal of memory and language, 59, 390-412.

Bartning, I., \& Schlyter, S. (2004). Itinéraires acquisitionnels et stades de développement en français L2. Journal of French language studies, 14(3), 281-299.

Bartoñ, K. (2018). MuMIn: Multi-Model Inference. R package version 1.40.4. https://CRAN.R-project.org/package=MuMIn

Bates, D., Maechler, M., Bolker, B., \& Walker, S. (2015). Fitting Linear Mixed-Effects Models Using lme4. Journal of Statistical Software, 67, 1-48. 
Bobb, S. C., \& Wodniecka, Z. (2013). Language switching in picture naming: What asymmetric switch costs (do not) tell us about inhibition in bilingual speech planning. Journal of Cognitive Psychology, 25(5), 568-585.

Calabria, M., Costa, A., Green, D. W. \& Abutalebi, J. (2018). Neural basis of bilingual language control. Annals of the New York Academy of Sciences, 1426(1), 221-235.

Comrie, B. (1976). Aspect: An introduction to the study of verbal aspect and related problems. Cambridge University Press.

Costa, A., \& Santesteban, M. (2004). Lexical access in bilingual speech production: Evidence from language switching in highly proficient bilinguals and L2 learners. Journal of memory and Language, 50(4), 491-511.

Costa, A., Santesteban, M., \& Ivanova, I. (2006). How do highly proficient bilinguals control their lexicalization process? Inhibitory and language-specific selection mechanisms are both functional. Journal of Experimental Psychology: Learning, Memory, and Cognition, 32(5), 1057.

Cunnings, I., Finlayson, I., \& Plonsky, L. (2015). Mixed effects modeling and longitudinal data analysis. In Plonsky, L (ed.), Advancing quantitative methods in second language research (pp. 159-181). Routledge.

Darcy, I., Mora, J. C., \& Daidone, D. (2014). Attention control and inhibition influence phonological development in a second language. Concordia Working Papers in Applied Linguistics, 5, 115-129.

Darcy, I., Mora, J. C., \& Daidone, D. (2016). The role of inhibitory control in second language phonological processing. Language Learning, 66(4), 741-773.

DeKeyser, R. M. (1997). Beyond explicit rule learning: Automatizing second language morphosyntax. Studies in second language acquisition, 19(2), 195-221. 
Ellis, N. C. (2008). The associative learning of constructions, learned attention, and the limited L2 endstate. Robinson, P. \& Ellis, N.C. (eds), Handbook of cognitive linguistics and second language acquisition (pp. 372-405) Routledge.

Ellis, N. C. Selective attention and transfer phenomena in L2 acquisition: Contingency, cue competition, salience, interference, overshadowing, blocking, and perceptual learning. Applied Linguistics, 27(2), 164-194.

Field, A., Miles, J., \& Field, Z. (2012). Discovering Statistics using R. Sage Publications.

Fink, A., \& Goldrick, M. (2015). Pervasive benefits of preparation in language switching. Psychonomic Bulletin \& Review, 22(3), 808-814.

Garbin, G., Costa, A., Sanjuan, A., Forn, C., Rodriguez-Pujadas, A., Ventura, N. E. E. A., ... \& Avila, C. (2011). Neural bases of language switching in high and early proficient bilinguals. Brain and Language, 119(3), 129-135.

Grabe, W. P., \& Stoller, F. L. (2013). Teaching and researching: Reading. Routledge.

Green, D. W. (1998). Mental control of the bilingual lexico-semantic system. Bilingualism: Language and Cognition, 1(2), 67-81.

Green, D. W., \& Abutalebi, J. (2013). Language control in bilinguals: The adaptive control hypothesis. Journal of Cognitive Psychology, 25(5), 515-530.

Henry, N., Culman, H., \& VanPatten, B. (2009). More on the effects of explicit information in instructed SLA: A partial replication and a response to Fernández (2008). Studies in Second Language Acquisition, 31(4), 559-575.

Hoffmann, L.-F. (1995). L'essentiel de la grammaire française. Prentice Hall

Howard, M. (2005). Les contextes prototypiques et marqués de l'emploi de l'imparfait par l'apprenant du français langue étrangère [The prototypical and marked contexts of Imperfect use by the advanced learner of French]. In E. Labeau \& P. Larrivée (Eds.), 
Nouveaux développements de l'imparfait [New developments of the Imperfect] (pp. 175197). New York, NY: Rodopi.

Hussey, E. K., \& Novick, J. M. (2012). The benefits of executive control training and the implications for language processing. Frontiers in psychology, 3, 158.

Izquierdo, J., \& Collins, L. (2008). The facilitative role of L1 influence in tense-aspect marking: A comparison of Hispanophone and Anglophone learners of French. The Modern Language Journal, 92(3), 350-368.

Jackson, C. N. (2007). The use and non-use of semantic information, word order, and case markings during comprehension by L2 learners of German. The Modern Language Journal, 91(3), 418-432.

Kaan, E. (2014). Predictive sentence processing in L2 and L1: What is different?. Linguistic Approaches to Bilingualism, 4(2), 257-282.

Kang, C., Ma, F., \& Guo, T. (2018). The plasticity of lexical selection mechanism in word production: ERP evidence from short-term language switching training in unbalanced Chinese-English bilinguals. Bilingualism: Language and Cognition, 21(2), 296-313.

Larson-Hall, J., \& Plonsky, L. (2015). Reporting and interpreting quantitative research findings: What gets reported and recommendations for the field. Language Learning, 65(S1), 127-159.

Leow, R. P. (2015). Explicit Learning in the L2 Classroom: A Student-Centered Approach. New York: Routledge.

Lim, H., \& Godfroid, A. (2015). Automatization in second language sentence processing: A partial, conceptual replication of Hulstijn, Van Gelderen, and Schoonen's 2009 study. Applied Psycholinguistics, 36(5), 1247-1282.

Linck, J. A., Hoshino, N., \& Kroll, J. F. (2008). Cross-language lexical processes and inhibitory control. The mental lexicon, 3(3), 349-374. 
Lorenzo, C. (2002). Les relations temporo-aspectuelles dans le récit oral en français et en castillan, langues premières et langues étrangères: étude transversale du stade ultime de l'acquisition d'une langue étrangère [Tempo-aspectual relations in oral retellings in French and Castilian as first and second languages: A crosslinguistic study of the end state of foreign language acquisition]. (Unpublished doctoral dissertation). Nanterre: Université de Nanterre - Paris X.

MacWhinney, B. (2012). The logic of the unified model. In Gass, S.M. \& Mackey, A. (eds), The Routledge handbook of second language acquisition (pp. 211-227). Routledge Marian, V., \& Spivey, M. (2003). Competing activation in bilingual language processing: Within-and between-language competition. Bilingualism: Language and Cognition, 6(2), 97-115.

McManus, K. (2013). Prototypical influence in second language acquisition: What now for the Aspect Hypothesis. International Review of Applied Linguistics in Language Teaching, 51(3), 299-322.

McManus, K. (2015). L1-L2 differences in the acquisition of form-meaning pairings in a second language. Canadian Modern Language Review, 71(2), 155-181.

McManus, K., \& Marsden, E. (2017). L1 explicit instruction can improve L2 online and offline performance. Studies in Second Language Acquisition, 39(3), 459-492.

McManus, K., \& Marsden, E. (2018). Online and offline effects of L1 practice in L2 grammar learning: A partial replication. Studies in Second Language Acquisition, 40(2), $459-475$.

McManus, K., \& Marsden, E. (2019a). Signatures of automaticity during practice: Explicit instruction about L1 processing routines can improve L2 grammatical processing. Applied Psycholinguistics, 40(1), 205-234. 
McManus, K., \& Marsden, E. (2019b). Using explicit instruction about L1 to reduce crosslinguistic effects in L2 grammar learning. Evidence from oral production in L2 French. The Modern Language Journal, 103(2)

Mercier, J., Pivneva, I., \& Titone, D. (2014). Individual differences in inhibitory control relate to bilingual spoken word processing. Bilingualism: Language and Cognition, 17(1), 89-117.

Meuter, R. F., \& Allport, A. (1999). Bilingual language switching in naming: Asymmetrical costs of language selection. Journal of Memory and Language, 40(1), 25-40.

Miyake, A., Friedman, N. P., Emerson, M. J., Witzki, A. H., Howerter, A., \& Wager, T. D. (2000). The unity and diversity of executive functions and their contributions to complex "frontal lobe" tasks: A latent variable analysis. Cognitive psychology, 41(1), 49-100.

Murakami, A. (2016). Modeling systematicity and individuality in nonlinear second language development: The case of English grammatical morphemes. Language Learning, 66, 834-871.

Nakagawa, S., \& Schielzeth, H. (2013). A general and simple method for obtaining R2 from generalized linear mixed-effects models. Methods in Ecology and Evolution, 4(2), 133142.

National Standards in Foreign Language Education Project (NSFLEP). (2015). WorldReadiness Standards For Learning Languages. Alexandria, VA: ACTFL

O'Grady, W. (2013). The illusion of language acquisition. Linguistic Approaches to Bilingualism, 3, 253-85.

O'Grady, W. (2005). Syntactic carpentry: An emergentist approach to syntax. Routledge.

O'Grady, W. (2012). Language acquisition without an acquisition device. Language Teaching, 45(1), 116-130. 
Pinheiro, J., Bates, D., DebRoy, S., \& Sarkar, D. \& R Core Team (2018). nlme: linear and nonlinear mixed effects models. R package version 3.1-137. https://CRAN.Rproject.org/package=nlme.

Plonsky, L., \& Oswald, F. L. (2017). Multiple regression as a flexible alternative to ANOVA in L2 research. Studies in Second Language Acquisition, 39(3), 579-592.

Prior, A., \& Gollan, T. H. (2011). Good language-switchers are good task-switchers: Evidence from Spanish-English and Mandarin-English bilinguals. Journal of the International Neuropsychological Society, 17(4), 682-691.

Prior, A., \& Gollan, T. H. (2013). The elusive link between language control and executive control: A case of limited transfer. Journal of Cognitive Psychology, 25(5), 622-645.

R Core Team (2018). R: A language and environment for statistical computing. R Foundation for Statistical Computing. Vienna, Austria. https://www.R-project.org/.

Roberts, L., \& Liszka, S. A. (2013). Processing tense/aspect-agreement violations on-line in the second language: A self-paced reading study with French and German L2 learners of English. Second Language Research, 29(4), 413-439.

Smith, C. S. (1997). The parameter of aspect. Springer.

Solovyeva, K., \& DeKeyser, R. (2018). Response time variability signatures of novel word learning. Studies in Second Language Acquisition, 40(1), 225-239.

Spada, N., Lightbown, P. M., \& White, J. (2005). The importance of form/meaning mappings in explicit form-focused instruction. In Housen, A. \& Pierrard, M. (eds). Investigations in Instructed Second Language Acquisition (pp. 199-234). New York: Gruyter.

Spivey, M. J., \& Marian, V. (1999). Cross talk between native and second languages: Partial activation of an irrelevant lexicon. Psychological Science, 10(3), 281-284. 
Stahl, C., Voss, A., Schmitz, F., Nuszbaum, M., Tüscher, O., Lieb, K., \& Klauer, K. C. (2014). Behavioral components of impulsivity. Journal of Experimental Psychology: General, 143, 850-886.

Starren, M. (2001). The second time: The acquisition of temporality in Dutch and French as a second language. Netherlands Graduate School of Linguistics.

Tagliamonte, S., \& Lawrence, H. (2000). “I Used to Dance, but I Don’t Dance Now” The Habitual Past in English. Journal of English Linguistics, 28(4), 324-353.

Timmer, K., Calabria, M., \& Costa, A. (2019). Non-linguistic effects of language switching training. Cognition, 182, 14-24.

Tu, L., Wang, J., Abutalebi, J., Jiang, B., Pan, X., Li, M., ... \& Huang, R. (2015). Language exposure induced neuroplasticity in the bilingual brain: A follow-up fMRI study. Cortex, 64, 8-19.

VanPatten, B. (2015). Input processing in adult SLA. In VanPatten, B \& Williams, J. (eds), Theories in second language acquisition: An introduction (pp. 113-134). Routledge

Wu, J., Kang, C., Ma, F., Gao, X., \& Guo, T. (2018). The influence of short-term languageswitching training on the plasticity of the cognitive control mechanism in bilingual word production. Quarterly Journal of Experimental Psychology, 71(10), 2115-2128.

Wu, Y. J., \& Thierry, G. (2010). Chinese-English bilinguals reading English hear Chinese. Journal of Neuroscience, 30(22), 7646-7651.

Zhang, H., Kang, C., Wu, Y., Ma, F., \& Guo, T. (2015). Improving proactive control with training on language switching in bilinguals. NeuroReport, 26(6), 354-359. 


\section{Notes}

1. Costa and Santesteban (2004) suggest that language selection mechanisms in unbalanced and balanced bilinguals are different. This discussion is not topicalized here given our focus on unbalanced bilinguals (or L2 learners). See also Bobb \& Wodniecka (2013).

\section{Acknowledgement}

A version of this paper was presented at the 2019 International Symposium on Bilingualism conference at the University of Alberta, Canada. This research was supported by a British Academy Postdoctoral Fellowship (PF130001). Many thanks to the learners who participated in this study, to Laurence Richard, Angela O'Flaherty, and Nigel Armstrong for help with recruitment, to Oriane Boulay and Alex Magnuson for research assistance, and to Emma Marsden for her mentorship. Thank you also to the two reviewers for their valuable feedback that greatly improved this paper. 


\section{Appendix}

Description of the treatment components Used in Session 1: Ongoingness (Present vs Past). For all Materials, see McManus and Marsden (2017) and IRIS

\begin{tabular}{|c|c|c|c|}
\hline & \multicolumn{2}{|c|}{ L2 } & $\mathbf{L 1}$ \\
\hline \multirow[t]{6}{*}{$\begin{array}{l}\text { Pre- } \\
\text { practice } \\
\text { EI }\end{array}$} & \multicolumn{2}{|c|}{$\begin{array}{l}\text { [Watch a six-second video clip of man } \\
\text { eating an apple. The apple was never } \\
\text { fully eaten.] }\end{array}$} & [Same video as L2-only treatment] \\
\hline & \multicolumn{2}{|c|}{$\begin{array}{l}\text { To describe this you could say: } \\
\text { Il mange une pomme } \\
\text { Or } \\
\text { Il mangeait une pomme }\end{array}$} & $\begin{array}{l}\text { To describe this you could say: } \\
\text { He is eating an apple } \\
\text { Or } \\
\text { He was eating an apple }\end{array}$ \\
\hline & \multicolumn{2}{|c|}{$\begin{array}{c}\text { The difference between these two is: } \\
\text { Il mange = ongoing action RIGHT } \\
\text { NOW } \\
\text { Il mangeait = ongoing action IN THE } \\
\text { PAST }\end{array}$} & $\begin{array}{l}\text { The difference between these two is: } \\
\text { 'he is eating' = ongoing action RIGHT } \\
\text { NOW } \\
\text { 'he was eating' = ongoing action IN PAST" }\end{array}$ \\
\hline & \multicolumn{2}{|c|}{$\begin{array}{l}\text { The ends of the verbs distinguish } \\
\text { between an ongoing action in the } \\
\text { present versus past e.g. [Four verbs } \\
\text { presented in pairs, aurally and in } \\
\text { writing]: }\end{array}$} & $\begin{array}{l}\text { To identify ongoing meaning in the present } \\
\text { versus the past, you need to focus on the } \\
\text { auxiliary. } \\
\text { Look/listen out for 'is' or 'was' to indicate }\end{array}$ \\
\hline & $\begin{array}{l}\text { Présent } \\
\text { RIGHT } \\
\text { NOW }\end{array}$ & $\begin{array}{l}\text { Imparfait } \\
\text { IN PAST }\end{array}$ & $\begin{array}{l}\text { RIGHT NOW (present) or it is one IN THE } \\
\text { PAST (past)." }\end{array}$ \\
\hline & $\begin{array}{c}\text { regarde } \\
\text { [RəgaRd] }\end{array}$ & $\begin{array}{l}\text { regardait } \\
\text { [RəgaRde] }\end{array}$ & \\
\hline
\end{tabular}

Practice 96 French items (48 listening, 48 reading).

Aim: Identify whether an ongoing event is taking place:

"MAINTENANT" (right now)
or
"DANS LE PASSÉ" (in the past)
Additional 32 English items (16 listening, 16 reading).

Aim: identify whether an ongoing event is taking place:

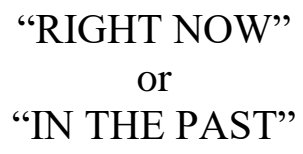


Example (English glosses not provided): Example:

Il...

(1) fait du shopping ('is shopping')

(2) faisait du shopping ('was shopping')
He...

(1) is eating a sandwich

(2) was eating a sandwich
EI given immediat ely after incorrect responses during practice
After incorrectly responding 'MAINTENANT':

"NOTE: The IMPARFAIT expresses an ongoing event DANS LE PASSÉ, not an ongoing event taking place MAINTENANT"

After incorrectly responding 'DANS LE PASSÉ':

"REMEMBER: The present tense in French expresses an ongoing event taking place MAINTENANT; not an ongoing action DANS LE PASSÉ",
After incorrectly responding 'RIGHT NOW':

"The present tense in English ('is +ing') and in French expresses the same meaning: ongoing action taking place RIGHT NOW',

After incorrectly responding 'IN THE PAST':

"The past tense in English ('was +ing') is the same as the IMP in French (-ait). They both express an ongoing action IN THE PAST' 


\section{Figures}

Figure 1.

Accuracy of L2>L1 switches over time per practice session for L2+L1 and L2+L1prac treatments
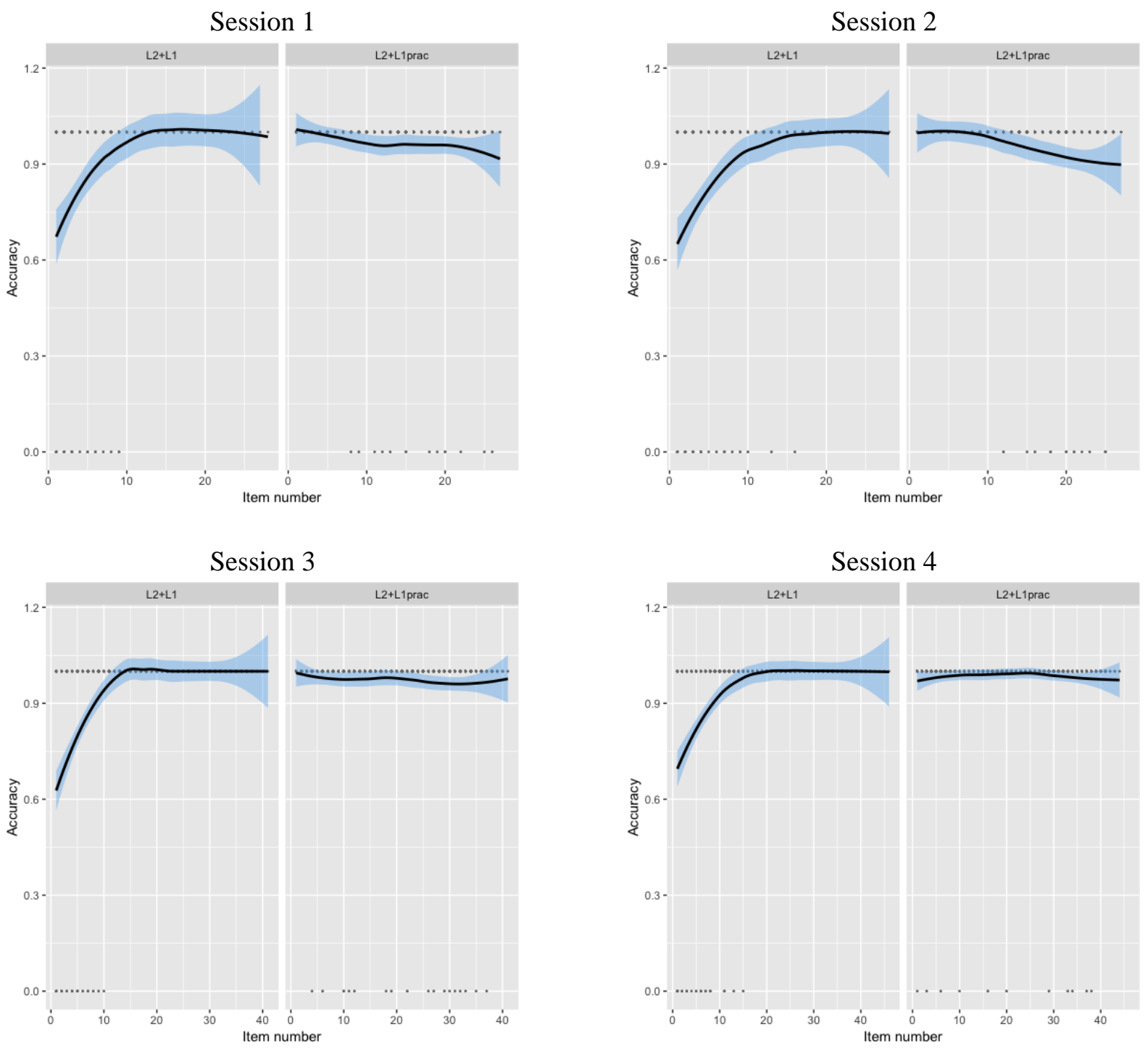

Note . Black line $=$ regression line, blue shading $=95 \%$ confidence intervals, grey dots $=$ individual data points 
Figure 2.

Accuracy of L1>L2 switches over time per practice session for L2+L1 and L2+L1prac treatments
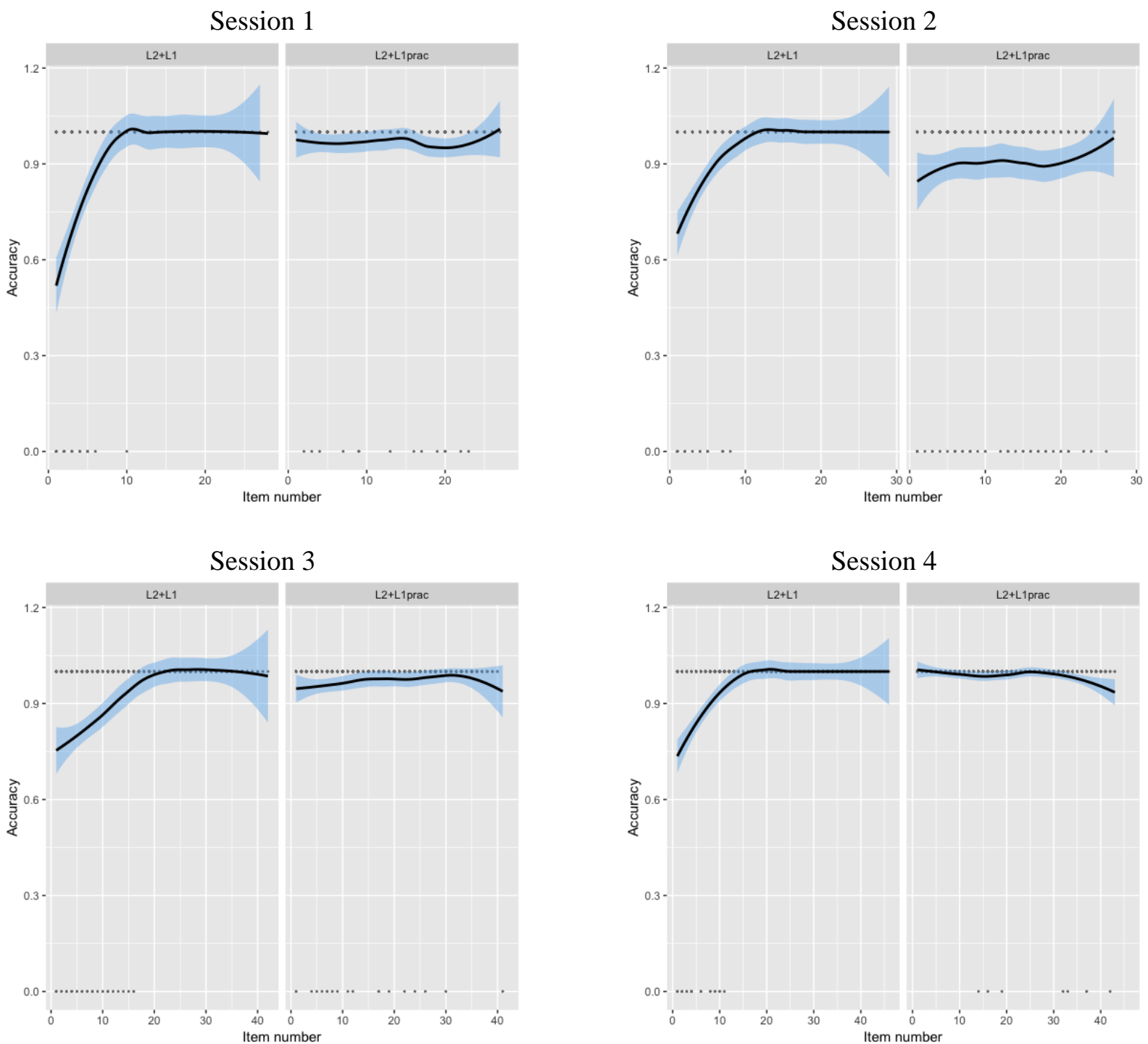

Note . Black line $=$ regression line, blue shading $=95 \%$ confidence intervals, grey dots $=$ individual data points 
Figure 3.

RTs of L2>L1 switches over time per practice session for $\mathrm{L} 2+\mathrm{L} 1$ and $\mathrm{L} 2+\mathrm{L} 1$ prac treatments
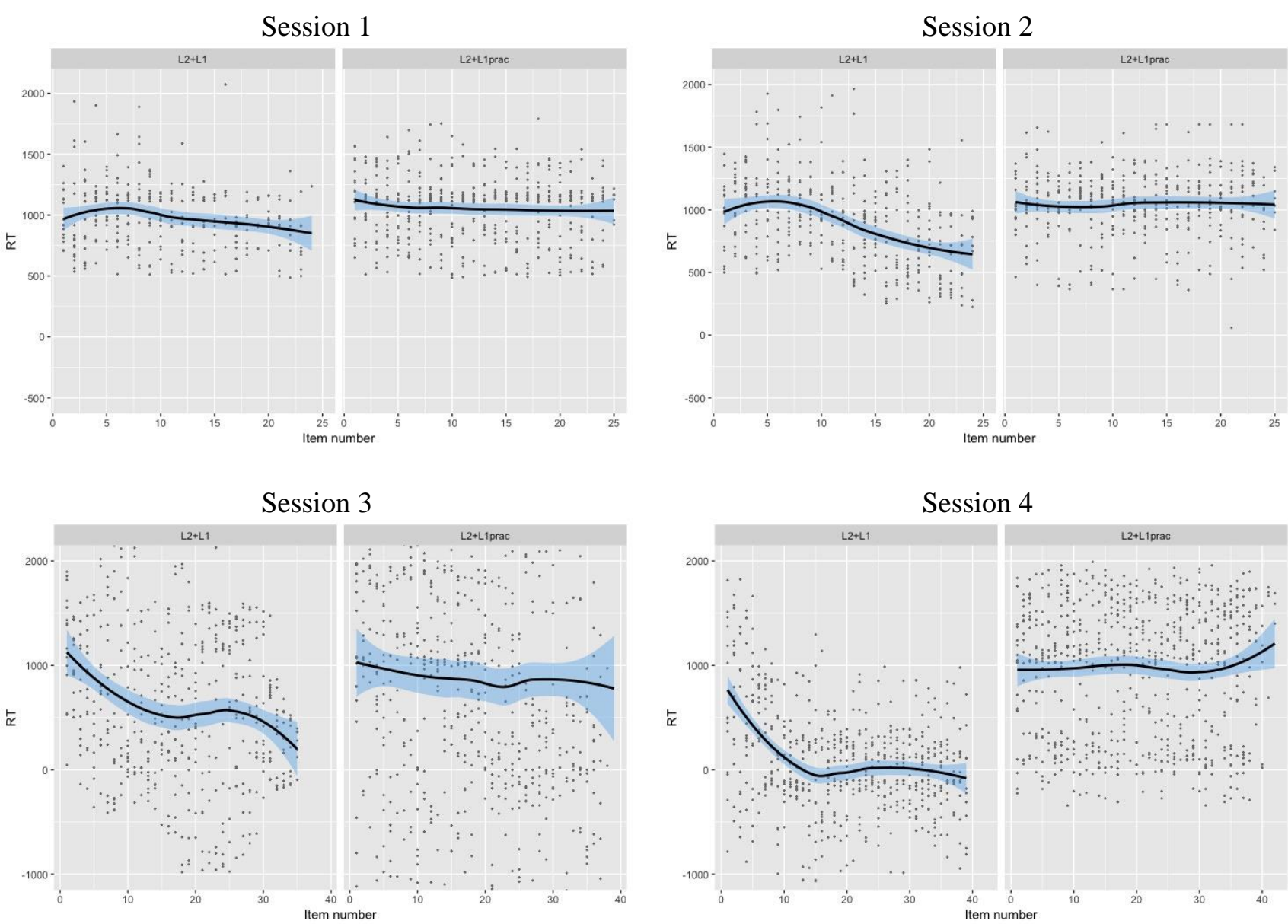

Note . Black line $=$ regression line, blue shading $=95 \%$ confidence intervals, grey dots $=$ individual data points 
Figure 4.

RTs of L1>L2 switches over time per practice session for $\mathrm{L} 2+\mathrm{L} 1$ and $\mathrm{L} 2+\mathrm{L} 1$ prac treatments
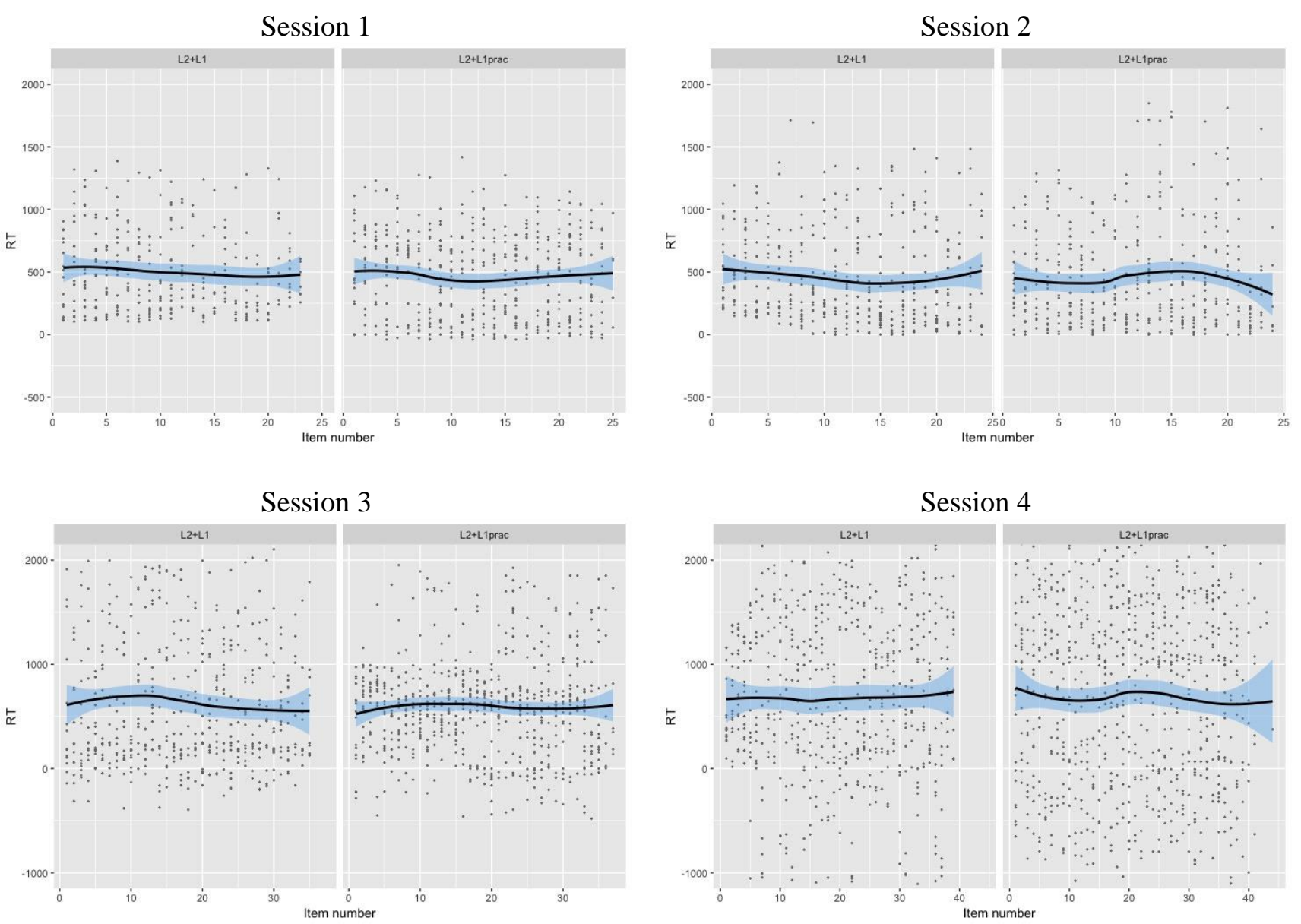

Note . Black line $=$ regression line, blue shading $=95 \%$ confidence intervals, grey dots $=$ individual data points 


\section{Tables}

Table 1.

Past habitual and past ongoing grammatical aspect meanings in French and English

\begin{tabular}{ll}
\hline Meaning & French sentence with English gloss \\
\hline Past habituality & Elle jouait au foot (e.g., tous les jours) \\
& 'She played / would play / used to play football (everyday)' \\
Past ongoingness & Elle jouait au foot (quand le téléphone a sonné) \\
& 'She was playing football (when the telephone rang)' \\
\hline
\end{tabular}


Table 2.

Summary of instructional components in the $\mathrm{L} 2+\mathrm{L} 1$ and $\mathrm{L} 2+\mathrm{L} 1$ prac treatments

\begin{tabular}{lcc}
\hline & L2+L1 treatment & L2+L1prac treatment \\
\hline EI about L1 & $\mathrm{X}$ & \\
EI about L2 & $\mathrm{X}$ & $\mathrm{X}$ \\
Comprehension practice of L1 sentences & $\mathrm{X}$ & $\mathrm{X}$ \\
Comprehension practice of L2 sentences & $\mathrm{X}$ & $\mathrm{X}$ \\
\hline
\end{tabular}


Table 3.

Summary of logit mixed-effects model comparisons for switch accuracy

\begin{tabular}{|c|c|c|c|c|c|c|c|c|}
\hline Session \# & Model & Fixed effects & Random effects & AIC & $\Delta \mathrm{AIC}$ & $\mathrm{BIC}$ & 2LL Statistic & $\mathrm{p}$ \\
\hline \multirow[t]{6}{*}{1} & Model 1 & None & By-Subject random-intercepts & -243.95 & & -227.84 & & \\
\hline & Model 2 & Model $1+$ Group & Same as Model 1 & -251.16 & -7.21 & -229.69 & 9.22 & 0.002 \\
\hline & Model 3 & Model 2 + Item & Same as Model 1 & -285.37 & -24.21 & -258.53 & 36.21 & $<.001$ \\
\hline & Model 4 & Model 3 + Trial & Same as Model 1 & -284.13 & 1.34 & -251.92 & 0.76 & 0.38 \\
\hline & Model 5 & Same as Model 4 & Model $1+$ by-Item random slope & -396.99 & -112.86 & -354.05 & 116.86 & $<.001$ \\
\hline & Model 6 & $\begin{array}{l}\text { Model } 5 \text { + Group X Item X } \\
\text { Trial interaction }\end{array}$ & Same as Model 5 & -402.03 & -5.04 & -337.61 & 13.04 & 0.01 \\
\hline \multirow[t]{6}{*}{2} & Model 1 & None & By-Subject random-intercepts & 159.54 & & 175.88 & & \\
\hline & Model 2 & Model 1 + Group & Same as Model 1 & 161.48 & 1.94 & 183.26 & 0.06 & 0.80 \\
\hline & Model 3 & Model 2 + Item & Same as Model 1 & 126.27 & -35.21 & 153.49 & 37.21 & $<.001$ \\
\hline & Model 4 & Model 3 + Trial & Same as Model 1 & 126.12 & -0.15 & 158.79 & 2.15 & 0.14 \\
\hline & Model 5 & Same as Model 4 & Model $1+$ by-Item random slope & 97.01 & -29.11 & 140.65 & 33.03 & $<.001$ \\
\hline & Model 6 & $\begin{array}{l}\text { Model } 5 \text { + Group X Item X } \\
\text { Trial interaction }\end{array}$ & Same as Model 5 & 57.65 & -39.36 & 122.99 & 47.44 & $<.001$ \\
\hline \multirow[t]{6}{*}{3} & Model 1 & None & By-Subject random-intercepts & -864.18 & & -846.76 & & \\
\hline & Model 2 & Model 1 + Group & Same as Model 1 & -870.86 & -6.68 & -847.64 & 8.69 & 0.003 \\
\hline & Model 3 & Model 2 + Item & Same as Model 1 & -950.88 & -80.02 & -921.86 & 82.02 & $<0.001$ \\
\hline & Model 4 & Model 3 + Trial & Same as Model 1 & -949.48 & 1.4 & -914.65 & 0.59 & 0.44 \\
\hline & Model 5 & Same as Model 4 & Model $1+$ by-Item random slope & -1023.06 & -73.58 & -976.62 & 77.58 & $<0.001$ \\
\hline & Model 6 & $\begin{array}{l}\text { Model } 5 \text { + Group X Item X } \\
\text { Trial interaction }\end{array}$ & Same as Model 5 & -1043.47 & -20.41 & -973.82 & 28.41 & $<0.001$ \\
\hline \multirow[t]{6}{*}{4} & Model 1 & None & By-Subject random-intercepts & -2191.92 & & -2174.18 & & \\
\hline & Model 2 & Model 1 + Group & Same as Model 1 & -2197.53 & -5.61 & -2173.87 & 7.61 & 0.006 \\
\hline & Model 3 & Model 2 + Item & Same as Model 1 & -2273.94 & -76.41 & -2244.37 & 78.41 & $<0.001$ \\
\hline & Model 4 & Model 3 + Trial & Same as Model 1 & -2272.43 & 1.51 & -2236.95 & 0.49 & 0.48 \\
\hline & Model 5 & Same as Model 4 & Model $1+$ by-Item random slope & -2364.52 & -92.09 & -2317.21 & 96.08 & $<0.001$ \\
\hline & Model 6 & $\begin{array}{l}\text { Model } 5 \text { + Group X Item X } \\
\text { Trial interaction }\end{array}$ & Same as Model 5 & -2403.23 & -38.71 & -2332.38 & 46.82 & $<0.001$ \\
\hline
\end{tabular}


Table 4.

Summary of mixed-effects linear model comparisons for switch RT

\begin{tabular}{|c|c|c|c|c|c|c|c|c|}
\hline Session \# & Model & Fixed effects & Random effects & AIC & $\Delta \mathrm{AIC}$ & $\mathrm{BIC}$ & 2LL Statistic & $\mathrm{p}$ \\
\hline \multirow[t]{6}{*}{1} & Model 1 & None & By-Subject random-intercepts & 22376.93 & & 22392.88 & & \\
\hline & Model 2 & Model $1+$ Group & Same as Model 1 & 22378.36 & 1.43 & 22399.62 & 0.57 & 0.45 \\
\hline & Model 3 & Model 2 + Item & Same as Model 1 & 22375.21 & -3.15 & 22401.79 & 5.15 & 0.02 \\
\hline & Model 4 & Model 3 + Trial & Same as Model 1 & 21505.36 & -869.85 & 21537.26 & 871.84 & $<0.001$ \\
\hline & Model 5 & Same as Model 4 & Model $1+$ by-Item random slope & 21512.61 & 7.25 & 21555.14 & 3.24 & 0.19 \\
\hline & Model 6 & $\begin{array}{l}\text { Model } 5 \text { + Group X Item X } \\
\text { Trial interaction }\end{array}$ & Same as Model 5 & 21500.18 & -12.43 & 21553.34 & 16.43 & $<0.001$ \\
\hline \multirow[t]{6}{*}{2} & Model 1 & None & By-Subject random-intercepts & 23467.09 & & 23483.15 & & \\
\hline & Model 2 & Model 1 + Group & Same as Model 1 & 23463.16 & -3.93 & 23484.58 & 5.93 & 0.01 \\
\hline & Model 3 & Model 2 + Item & Same as Model 1 & 23456.25 & -6.91 & 23483.02 & 8.91 & 0.002 \\
\hline & Model 4 & Model 3 + Trial & Same as Model 1 & 22763.36 & -692.89 & 22795.49 & 694.88 & $<0.001$ \\
\hline & Model 5 & Same as Model 4 & Model $1+$ by-Item random slope & 22757.90 & -5.46 & 22800.74 & 9.46 & 0.008 \\
\hline & Model 6 & $\begin{array}{l}\text { Model } 5 \text { + Group X Item X } \\
\text { Trial interaction }\end{array}$ & Same as Model 5 & 22701.63 & -56.27 & 22765.89 & 64.27 & $<.001$ \\
\hline \multirow[t]{6}{*}{3} & Model 1 & None & By-Subject random-intercepts & 38469.15 & & 38486.45 & & \\
\hline & Model 2 & Model 1 + Group & Same as Model 1 & 38462.27 & -6.88 & 38485.33 & 8.88 & 0.003 \\
\hline & Model 3 & Model 2 + Item & Same as Model 1 & 38453.76 & -8.51 & 38482.59 & 10.51 & $<0.001$ \\
\hline & Model 4 & Model 3 + Trial & Same as Model 1 & 38432.57 & -21.19 & 38467.16 & 23.19 & $<0.001$ \\
\hline & Model 5 & Same as Model 4 & Model $1+$ by-Item random slope & 38432.07 & -0.50 & 38478.19 & 4.49 & 0.11 \\
\hline & Model 6 & $\begin{array}{l}\text { Model } 5 \text { + Group X Item X } \\
\text { Trial interaction }\end{array}$ & Same as Model 5 & 38409.98 & -22.09 & 38479.16 & 30.09 & $<0.001$ \\
\hline \multirow[t]{6}{*}{4} & Model 1 & None & By-Subject random-intercepts & 42361.56 & & 42379.18 & & \\
\hline & Model 2 & Model 1 + Group & Same as Model 1 & 42325.12 & -36.44 & 42348.62 & 38.44 & $<0.001$ \\
\hline & Model 3 & Model 2 + Item & Same as Model 1 & 42319.02 & -6.1 & 42348.40 & 8.09 & 0.004 \\
\hline & Model 4 & Model 3 + Trial & Same as Model 1 & 42312.29 & -6.73 & 42347.55 & 8.73 & 0.003 \\
\hline & Model 5 & Same as Model 4 & Model $1+$ by-Item random slope & 42315.36 & 3.07 & 42362.37 & 0.93 & 0.63 \\
\hline & Model 6 & $\begin{array}{l}\text { Model } 5 \text { + Group X Item X } \\
\text { Trial interaction }\end{array}$ & Same as Model 5 & 42059.95 & -255.41 & 42130.47 & 263.40 & $<0.001$ \\
\hline
\end{tabular}


Table 5.

$\mathrm{R}^{2}$ values per practice session for the fixed effects only (marginal $\mathrm{R}^{2}$ ) and the entire model (conditional $\mathrm{R}^{2}$ )

\begin{tabular}{lcc}
\hline & Marginal $\mathrm{R}^{2}$ & Conditional R $^{2}$ \\
\cline { 2 - 3 } Session 1 & & \\
Accuracy & 0.04 & 0.10 \\
RT & 0.45 & 0.45 \\
Session 2 & & \\
Accuracy & 0.06 & 0.08 \\
RT & 0.39 & 0.39 \\
Session 3 & & \\
Accuracy & 0.09 & 0.06 \\
RT & 0.03 & 0.04 \\
Session 4 & & \\
Accuracy & 0.11 & 0.07 \\
RT & 0.17 & 0.17 \\
\hline
\end{tabular}


Table 6.

Summary of fixed effects for switch accuracy

\begin{tabular}{|c|c|c|c|c|c|c|c|}
\hline Session \# & Parameter & Estimate & $95 \%$ CIs for estimate & SE & df & $\mathrm{t}$ & $\mathrm{p}$ \\
\hline \multirow[t]{8}{*}{1} & (intercept) & 0.99 & $0.95,1.03$ & 0.02 & 1551 & 47.97 & $<0.001$ \\
\hline & Group & -0.12 & $-0.21,-0.04$ & 0.04 & 1551 & -2.88 & 0.004 \\
\hline & Item & -0.00 & $-00,0.00$ & 0.00 & 26 & -1.36 & 0.19 \\
\hline & Trial & -0.03 & $-0.84,0.03$ & 0.03 & 1551 & -1.04 & 0.30 \\
\hline & Group X Item & 0.01 & $0.00,0.01$ & 0.00 & 1551 & 2.92 & 0.003 \\
\hline & Group X Trial & -0.04 & $-0.12,0.04$ & 0.04 & 1551 & -0.89 & 0.37 \\
\hline & Item X Trial & 0.00 & $0.00,0.01$ & 0.00 & 1551 & 1.01 & 0.31 \\
\hline & Group X Item X Trial & 0.00 & $-.00,0.01$ & 0.00 & 1551 & 0.71 & 0.48 \\
\hline \multirow[t]{8}{*}{2} & (intercept) & 1.03 & $0.98,1.08$ & 0.03 & 1677 & 40.25 & $<0.001$ \\
\hline & Group & -0.25 & $-0.33,-0.18$ & 0.04 & 1677 & -6.66 & $<0.001$ \\
\hline & Item & -0.01 & $-0.01,-0.00$ & 0.00 & 27 & -2.92 & 0.007 \\
\hline & Trial & -0.15 & $-0.22,-0.09$ & 0.03 & 1677 & -4.55 & $<0.001$ \\
\hline & Group X Item & 0.02 & $0.01,0.02$ & 0.00 & 1677 & 6.46 & $<0.001$ \\
\hline & Group X Trial & 0.20 & $0.11,0.29$ & 0.05 & 1677 & 4.27 & $<0.001$ \\
\hline & Item X Trial & 0.01 & $0.00,0.01$ & 0.00 & 1677 & 3.22 & 0.001 \\
\hline & Group X Item X Trial & -0.01 & $-0.02,-0.00$ & 0.00 & 1677 & -2.92 & 0.004 \\
\hline \multirow[t]{8}{*}{3} & (intercept) & 0.99 & $9.58,1.02$ & 0.02 & 2404 & 64.82 & $<0.0001$ \\
\hline & Group & -0.16 & $-0.21,-0.10$ & 0.03 & 2404 & -5.78 & $<0.0001$ \\
\hline & Item & -0.00 & $-0.00,0.00$ & 0.00 & 40 & -1.06 & 0.29 \\
\hline & Trial & -0.03 & $-0.08,0.01$ & 0.02 & 2404 & -1.65 & 0.09 \\
\hline & Group X Item & 0.01 & $0.00,0.01$ & 0.00 & 2404 & 5.63 & $<0.0001$ \\
\hline & Group X Trial & 0.00 & $-0.04,0.08$ & 0.03 & 2404 & 0.57 & 0.57 \\
\hline & Item X Trial & 0.00 & $-0.00,0.00$ & 0.00 & 2404 & 1.87 & 0.06 \\
\hline & Group X Item X Trial & -0.00 & $-0.00,0.00$ & 0.00 & 2404 & -1.19 & 0.23 \\
\hline
\end{tabular}


Bilingualism: Language and Cognition, accepted for publication 21 February 2020

\begin{tabular}{cccccccc} 
(intercept) & 0.99 & $0.96,1.01$ & 0.01 & 2683 & 83.74 & $<.0001$ \\
Group & -0.15 & $-0.19,-0.11$ & 0.02 & 2683 & -6.95 & $<.0001$ \\
Item & -0.00 & $-0.00,0.00$ & 0.00 & 44 & -0.19 & 0.84 \\
Trial & 0.02 & $-0.01,0.05$ & 0.02 & 2683 & 1.06 & 0.29 \\
Group X Item & 0.01 & $0.00,0.01$ & 0.00 & 2683 & 6.06 & $<.0001$ \\
Group X Trial & 0.00 & $-0.05,0.04$ & 0.02 & 2683 & 0.04 & 0.97 \\
Item X Trial & -0.00 & $-0.00,0.00$ & 0.00 & 2683 & -0.93 & 0.35 \\
Group X Item X Trial & 0.00 & $-0.00,0.00$ & 0.00 & 2683 & 0.08 & 0.94 \\
\hline
\end{tabular}


Table 7.

Posthoc results for within-group accuracy switches over time in each practice session

\begin{tabular}{|c|c|c|c|c|c|c|}
\hline & $\mathrm{b}$ & CIs & $\mathrm{df}$ & $\mathrm{t}$ & $\mathrm{p}$ & $\mathrm{R}^{2}$ \\
\hline \multicolumn{7}{|l|}{ Session 1} \\
\hline $\mathrm{L} 2+\mathrm{L} 1$ & 0.01 & $0.01,0.02$ & 26 & 9.55 & $<0.001$ & 0.16 \\
\hline $\mathrm{L} 2+\mathrm{L} 1 \mathrm{prac}$ & -0.00 & $-0.00,0.00$ & 25 & -1.64 & 0.10 & 0.01 \\
\hline \multicolumn{7}{|l|}{ Session 2} \\
\hline $\mathrm{L} 2+\mathrm{L} 1$ & 0.01 & $0.01,0.01$ & 27 & 10.58 & $<0.001$ & 0.16 \\
\hline L2+L1prac & -0.00 & $-0.00,0.00$ & 25 & -0.85 & 0.39 & 0.00 \\
\hline \multicolumn{7}{|l|}{ Session 3} \\
\hline L2+L1 & 0.01 & $0.01,0.01$ & 40 & 11.69 & $<0.001$ & 0.14 \\
\hline L2+L1prac & 0.00 & $-0.00,0.00$ & 39 & 0.52 & 0.59 & 0.00 \\
\hline \multicolumn{7}{|l|}{ Session 4} \\
\hline L2+L1 & 0.00 & $0.00,0.01$ & 44 & 6.48 & $<0.001$ & 0.13 \\
\hline $\mathrm{L} 2+\mathrm{L} 1$ prac & -0.00 & $-0.00,0.00$ & 42 & -1.45 & 0.16 & 0.00 \\
\hline
\end{tabular}


Table 8 .

Summary of fixed effects for switch RT

\begin{tabular}{|c|c|c|c|c|c|c|c|}
\hline Session \# & Parameter & Estimate & $95 \%$ CIs for estimate & $\mathrm{SE}$ & $\mathrm{df}$ & $\mathrm{t}$ & $\mathrm{p}$ \\
\hline \multirow[t]{8}{*}{1} & (intercept) & 1090.63 & $1030.79,1150.46$ & 30.58 & 1462 & 35.66 & $<.001$ \\
\hline & Group & -28.51 & $-121.59,64.58$ & 45.93 & 34 & -0.62 & 0.54 \\
\hline & Item & -2.91 & $-7.02,1.21$ & 2.10 & 1462 & -1.38 & 0.18 \\
\hline & Trial & -597.89 & $-679.85,-515.93$ & 41.89 & 1462 & -14.27 & $<.001$ \\
\hline & Group X Item & -4.41 & $-11.15,2.33$ & 3.45 & 1462 & -1.28 & 0.20 \\
\hline & Group X Trial & 88.27 & $-34.98,211.52$ & 62.99 & 1462 & 1.40 & 0.16 \\
\hline & Item X Trial & 1.05 & $-4.78,6.85$ & 2.97 & 1462 & 0.35 & 0.73 \\
\hline & Group X Item X Trial & 1.61 & $-7.87,11.11$ & 4.85 & 1462 & 0.33 & 0.74 \\
\hline \multirow[t]{8}{*}{2} & (intercept) & 1032.98 & $961.58,1104.37$ & 36.49 & 1524 & 28.31 & $<.001$ \\
\hline & Group & 108.45 & $2.75,214.15$ & 52.03 & 32 & 2.08 & 0.05 \\
\hline & Item & 1.03 & $-3.96,6.02$ & 2.55 & 1524 & 0.40 & 0.67 \\
\hline & Trial & -590.17 & $-686.79,-493.54$ & 49.39 & 1524 & -11.95 & $<.001$ \\
\hline & Group X Item & -22.01 & $-29.24,-14.78$ & 3.69 & 1524 & -5.96 & $<.001$ \\
\hline & Group X Trial & -56.64 & $-193.81,80.52$ & 70.11 & 1524 & -0.81 & 0.42 \\
\hline & Item X Trial & -0.53 & $-7.49,6.43$ & 3.56 & 1524 & -0.15 & 0.88 \\
\hline & Group X Item X Trial & 18.43 & $8.47,28.39$ & 5.09 & 1524 & 3.62 & $<.001$ \\
\hline \multirow[t]{8}{*}{3} & (intercept) & 962.43 & $820.64,1104.22$ & 72.43 & 2317 & 13.29 & $<.001$ \\
\hline & Group & -43.72 & $-260.19,172.76$ & 110.58 & 2317 & -0.39 & 0.69 \\
\hline & Item & -4.07 & $-10.68,2.55$ & 3.38 & 2317 & -1.20 & 0.23 \\
\hline & Trial & -371.49 & $-550.92,-192.07$ & 91.65 & 2317 & -4.05 & $<.001$ \\
\hline & Group X Item & -13.27 & $-23.66,-2.88$ & 5.31 & 2317 & -2.50 & 0.01 \\
\hline & Group X Trial & 156.68 & $-117.87,431.22$ & 140.24 & 2317 & 1.12 & 0.26 \\
\hline & Item X Trial & 4.23 & $-4.31,12.78$ & 4.36 & 2317 & 0.97 & 0.33 \\
\hline & Group X Item X Trial & 8.48 & $-5.01,21.96$ & 6.89 & 2317 & 1.23 & 0.29 \\
\hline
\end{tabular}


Preprint version

Bilingualism: Language and Cognition, accepted for publication 21 February 2020

Kevin McManus, kmcmanus@psu.edu

\begin{tabular}{ccccccc} 
(intercept) & 961.71 & $843.80,1079.61$ & 60.22 & 2594 & 15.97 & $<.001$ \\
Group & -577.33 & $-762.46,-392.19$ & 91.03 & 32 & -6.34 & $<.001$ \\
Item & 0.45 & $-4.25,5.14$ & 2.40 & 2594 & 0.19 & 0.85 \\
Trial & -230.61 & $375.41,-85.80$ & 73.96 & 2594 & -3.12 & $<.001$ \\
Group X Item & -14.88 & $-22.05,-7.72$ & 3.66 & 2594 & -4.07 & $<.001$ \\
Group X Trial & 512.52 & $292.98,732.07$ & 112.13 & 2594 & 4.57 & $<.001$ \\
Item X Trial & -3.42 & $-9.70,2.86$ & 3.21 & 2594 & -1.07 & 0.29 \\
up X Item X Trial & 18.57 & $8.94,28.21$ & 4.92 & 2594 & 3.77 & $<.001$ \\
\hline
\end{tabular}


Table 9.

Posthoc results for within-group switch costs over time in practice sessions 2 and 4 for L2>L1 and L1>L2 switches

\begin{tabular}{|c|c|c|c|c|c|c|}
\hline & $\mathrm{b}$ & CIs & df & $\mathrm{t}$ & $\mathrm{p}$ & $\mathrm{R}^{2}$ \\
\hline \multicolumn{7}{|l|}{ L1>L2 } \\
\hline \multicolumn{7}{|l|}{ Session 2} \\
\hline $\mathrm{L} 2+\mathrm{L} 1$ & -3.05 & $-10.19,4.09$ & 370 & -0.84 & 0.40 & 0.00 \\
\hline L2+L1prac & 1.03 & $-2.74,4.80$ & 383 & 0.54 & 0.59 & 0.00 \\
\hline \multicolumn{7}{|l|}{ Session 4} \\
\hline L2+L1 & 0.59 & $-5.94,6.22$ & 559 & 0.21 & 0.84 & 0.00 \\
\hline $\mathrm{L} 2+\mathrm{L} 1$ prac & 0.69 & $-3.26,4.64$ & 719 & 0.34 & 0.73 & 0.00 \\
\hline \multicolumn{7}{|l|}{ L2>L1 } \\
\hline \multicolumn{7}{|l|}{ Session 2} \\
\hline L2+L1 & -20.93 & $-25.49,-16.35$ & 369 & -8.98 & $<0.001$ & 0.17 \\
\hline L2+L1prac & 0.38 & $-5.77,6.53$ & 370 & 0.12 & 0.90 & 0.00 \\
\hline \multicolumn{7}{|l|}{ Session 4} \\
\hline L2+L1 & -14.34 & $-17.91,-10.78$ & 559 & -7.89 & 0.001 & 0.10 \\
\hline L2+L1 prac & -2.89 & $-8.28,2.50$ & 725 & -1.05 & 0.29 & 0.00 \\
\hline
\end{tabular}

